PontIFícIA UNIVERSIDADE CATÓLICA dO RIO DE JANEIRO

Trabalho Remoto: Aplicação de projeto piloto em Furnas

Thiago Teber Santos Torres

Trabalho de Conclusão de Curso

Centro de Ciências socials - CCS DEPARTAMENTO DE ADMINISTRAÇÃO

Graduação em Administração de Empresas 


\section{Trabalho Remoto: Aplicação de projeto piloto em Furnas}

Trabalho de Conclusão de Curso

Trabalho de Conclusão de Curso, apresentado ao programa de graduação em Administração da PUC-Rio como requisito parcial para a obtenção do titulo de graduação em Administração.

Orientador(a): Marcelo Piñeiro

Rio de Janeiro

05 de Junho de 2018. 


\section{Agradecimentos}

Foram anos de estudos árduos até chegar aqui e apesar de todo esforço destinado a realização desse último trabalho voltado a graduação, encerro esse ciclo com a certeza do dever cumprido.

Preciso agradecer a diversas pessoas que certamente foram fundamentais para que eu chegasse até esse momento.

Primeiramente gostaria de agradecer a minha família, pois sempre me apoiaram, fazendo de tudo para que esse sonho se realizasse e com certeza são meus maiores motivos de conseguir. Esse primeiro agradecimento vai a Marcia Cristina Santos Torres, minha mãe, Magali dos Santos Costa, minha avó, Ana Cristina dos Santos Costa, minha madrinha, e a Bruno Teber Santos Torres, Bruna Costa da Silva e Thais Costa da Silva, meus irmãos.

Em segundo lugar gostaria de agradecer a minha companheira de vida, que soube ser paciente em momentos de destempero causados pelo estresse das provas e trabalhos cada vez mais difíceis e sempre me apoiou a concretizar esse sonho, Ulli Grantham Vieira, muito obrigado por tudo.

Em terceiro lugar, gostaria de agradecer ao Vice-Reitor Comunitário, professor Augusto Sampaio por ter confiado no meu potencial e me concedido uma bolsa integral de estudo, pois certamente sem isso, não teria chegado a esse momento.

Por fim, porém não menos importante, gostaria de agradecer ao Professor Marcelo Piñeiro, meu orientador, por toda paciência e auxílio nessa reta final de curso e a professora Bianca Fonseca, Caetano Almeida, Felipe Grantham, Luiz Gustavo Blanco, Patricia Grantham pela disponibilidade no auxílio para a conclusão desse trabalho e principalmente a Marcia Cristina Castro por toda contribuição para a obtenção de materiais primordiais a execução do mesmo.

Certamente encerro esse ciclo feliz, realizado e pronto para os próximos que virão, porém, sempre me lembrando de onde vim e onde tudo começou, para sempre um morador do Horto e filho da PUC. 


\section{Resumo}

Teber Santos Torres, Thiago. Fernandez Piñeiro, Marcelo. Trabalho Remoto: Aplicação de projeto piloto em Furnas. Rio de Janeiro, 2018. 55 p. Trabalho de Conclusão de Curso - Departamento de Administração. Pontifícia Universidade Católica do Rio de Janeiro. Tendo em vista as constantes mudanças pelas quais o mercado de trabalho moderno passa, cada vez mais as organizações sentem necessidade de novas formas de trabalho para se adaptarem aos mesmos. A partir disso, trazemos como tema central desse trabalho de conclusão de curso o trabalho remoto, também conhecido como home office. Buscamos implantar um projeto piloto na área de Tecnologia da Informação da empresa Furnas, para responder ao nosso problema de estudo. A adoção do trabalho remoto pode aumentar a produtividade de uma organização?

Palavras- chave

Trabalho Remoto; Furnas; Projeto Piloto.

\section{Abstract}

Teber Santos Torres, Thiago. Fernandez Piñeiro, Marcelo. Home Office: Application of pilot project on Furnas Company. Rio de Janeiro, 2018. 55 p. Final Course Assignment - Departament of Administration. Pontifical Catholic University of Rio de Janeiro.

Considering the constant changes of modern labour market, more and more organizations needs new ways of working to adapt their process. Therefore, the main topic of this final course assignment is Home Office, a practice that has been growing in recent years. So, we seek to implement a pilot project on Information Technology (IT) departament of Furnas Company, looking for answers to our study problem. The adopting Home Office by organizations increase the productivity?

Key-words

Remote Work; Furnas; Pilot Project. 


\section{Sumário}

1 O tema e o problema de estudo 1

1.1. Introdução ao tema e ao problema do estudo 1

1.2. Objetivo do estudo 4

1.3. Objetivos intermediários do estudo 4

1.4. Delimitação e foco do estudo 5

1.5. Justificativa e relevância do estudo 5

2 Revisão de literatura $\quad 7$

2.1. Trabalho e Tecnologia na Contemporaneidade 7

2.2. Trabalho Remoto 9

2.3. Comportamento Organizacional 15

$\begin{array}{ll}\text { 2.4. Produtividade } & 18\end{array}$

2.5. Absenteísmo 20

3 Métodos e procedimentos de coleta e de análise de dados do estudo 23

3.1. Etapas de coleta de dados 23

3.2. Fontes de informação selecionadas para coleta de dados no estudo 24

3.3. Procedimentos e instrumentos de coleta de dados utilizados no $\begin{array}{ll}\text { estudo } & 25\end{array}$

3.4. Formas de tratamento e análise dos dados coletados para o estudo 27

3.5. Limitações do Estudo 29

4 Apresentação e análise dos resultados 30

4.1. A Empresa 30

4.2. Descrição da amostra / do perfil dos entrevistados 31

4.3. Descrição e análise dos resultados do método quantitativo 31

4.4. Descrição e análise dos resultados do método qualitativo 35

5 Conclusões e recomendações para novos estudos 37

5.1. Sugestões e recomendações para novos estudos 39 


\section{Lista de figuras}

Figura 1: Pesquisa sobre desperdício de tempo no trabalho (SBCoaching, 2015)

Figura 2: Pirâmide dos aspectos visíveis e invisíveis do comportamento organizacional (Chiavenato, 2014) ....................................................... 16

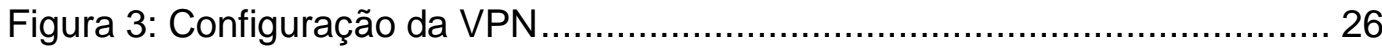

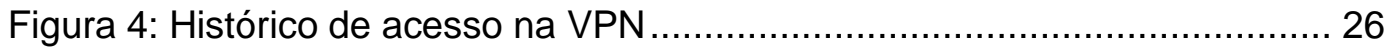

Figura 5: Regra de 3 para o cálculo do ganho de produtividade....................... 28

Figura 6: Tabela de Produtividade ............................................................. 32

Figura 7: Gráfico de ganho produtivo dos participantes do projeto piloto........... 33

Figura 8: Ficha de controle de atividades ................................................... 34

Figura 9: Redução de custo propiciado pelo trabalho remoto ............................ 34

\section{Lista de Tabelas}

Tabela 1: Participantes do projeto piloto e seus respectivos cargos .................. 25

Tabela 2: Gerentes participantes do projeto piloto e seus respectivos cargos ... 25 


\section{O tema e o problema de estudo}

Esse capítulo volta-se à apresentação do tema que se pretende desenvolver e do problema de estudo.

Assim, apresenta-se o problema que suscitou a proposta de investigação e respectivos objetivos de pesquisa. Na sequência, são indicadas as suposições e as hipóteses do estudo e se informa a relevância e justificativa do estudo e a delimitação e foco do estudo.

\subsection{Introdução ao tema e ao problema do estudo}

É de conhecimento geral a dinamicidade dos mercados atuais, sem contar com a globalização dos mesmos. Sabendo disso, se manter competitivo tornouse cada vez mais difícil, fazendo com que as grandes empresas busquem novas formas de estruturação, modificando as antes assumidas como padrões. Cada vez mais se faz necessário que os colaboradores das grandes organizações estejam sempre preparados para as mudanças do mercado de trabalho, conseguindo uma adaptação rápida e eficiente aos mais diversos cenários possíveis, além, de um bom entendimento sobre as estratégias da empresa e a sensação de serem fundamentais para o alcance das metas. Porém, em função do formato atual de trabalho, que exclui um grande número de trabalhadores, possuir funcionários com tais capacidades se tornou um grande desafio, logo, é cada vez menos raro ver empresas optando por funcionários que possuem experiências diferentes no mercado de trabalho, se tornando cada vez menos importante uma carreira de longo prazo em determinado setor.

De acordo com Batista, Antunes e lizuka (2012) as organizações contemporâneas buscam a qualidade dos seus serviços e produtos para se manterem no mercado competitivo e globalizado, apostando no capital humano como seu diferencial. 
Essas alterações no modo de pensar organizacional vêm transformando também as estruturas antes padronizadas de trabalho, e atualmente é comum encontrar trabalhadores contratados para exercer atividades específicas, ou que mesmo possuindo vínculo empregatício, exercem suas tarefas diretamente de seus domicílios, ou até mesmo pessoas que cumprem funções em determinado espaço físico da organização, mas que se reportam a superiores em outros estados ou países.

Segundo Schirigatti e Kasprzak (2007), a partir das evoluções tecnológicas tornou-se possível o funcionário exercer a mesma função antes exercida no escritório, de sua própria residência, sendo necessários apenas alguns instrumentos como notebook, internet e softwares utilizados pela empresa, ligados por uma rede que conectaria toda a organização.

O fenômeno da globalização, conjuntamente as reestruturações organizacionais buscando vantagens competitivas em mercados cada vez menos estáveis e a diminuição das distâncias causadas pelo avanço tecnológico, gerou também novas formas de relação trabalhista. Antes se entendia como empregado, alguém que exercesse determinada função, em período integral e em determinado espaço físico de uma organização, porém, atualmente, existem empregados de meio período, terceirizados, contratados especificamente para determinada atividade, entre outras formas que visam flexibilizar o trabalho.

Baseado nessa o trabalho tras como tema central desse trabalho de conclusão de curso, o home office, também chamado de trabalho remoto, trabalho a distância ou trabalho em casa, que surge como uma alternativa flexível de estruturação de trabalho, que pode unir a qualidade de vida dos colaboradores a eficiência produtiva da organização.

O trabalho remoto começou nos Estados Unidos, porém vem se tornando tendência entre as grandes empresas globais, pois apresenta uma redução grande no custo gerado pelos funcionários, uma vez que os mesmos não têm necessidade de deslocamento, além de pequenos custos ligados a água, luz, café e etc. Além dos custos reduzidos para a empresa, nota-se também redução de custos para a sociedade, pois quanto menor o número de funcionários com necessidade de se dirigir as empresas, menor será a quantidade de carros nas ruas e consequentemente menor será o trânsito nas grandes capitais.

Em seu livro, RIFKIN (1996, p. 8), cita duas empresas que optaram pela flexibilização do trabalho buscando reduzir seus custos: 


\begin{abstract}
Comprimindo o tempo e flexibilizando o espaço, a nova mágica eletrônica transformou a própria ideia de escritório, de conceito espacial para temporal. Empresas, como AT\&T, começaram a introduzir a ideia de "escritório virtual". Os funcionários são equipados com escritórios móveis, completo com laptop, fax e telefone celular e, literalmente, mandados para casa. (...) A Ernst and Young, empresa de auditoria com sede em Nova lorque, recentemente reduziu seu espaço físico de 35 mil para 28 mil metros quadrados e instituiu um programa de "hotelaria". Todos os funcionários abaixo do nível sênior foram "desalojados" de suas mesas. Agora quando querem usar um escritório, precisam fazer uma reserva com antecedência.
\end{abstract}

Outro grande benefício é quanto à qualidade de vida dos colaboradores, pois se tratando de uma estrutura de trabalho flexível, permite que o colaborador organize seu tempo da maneira que julgar adequado.

Apesar da grande maioria dos autores apresentarem uma visão positiva de tais mudanças nas estruturas de trabalho, existem alguns que observam pontos negativos, tais como, o fim das proteções.

No Brasil, o trabalho remoto se tornou efetivo, na década de 90 , porém, tem sido percebido ora como oportunidade de redução de custos e criação de vantagens competitivas, ora como ameaça a aspectos cruciais das relações trabalhistas, como jornada de trabalho, 13ํㅗ salário, cálculo de horas extras, etc.

Em 2011, a lei que iguala os trabalhadores remotos aos demais trabalhadores foi aprovada (Cg. Artigo 6º da CLT e seu parágrafo único).

\begin{abstract}
Art. 6․ Não se distingue entre o trabalho realizado no estabelecimento do empregador, o executado no domicílio do empregado e o realizado a distância, desde que estejam caracterizados os pressupostos da relação de emprego. Parágrafo único. Os meios telemáticos e informatizados de comando, controle e supervisão se equiparam, para fins de subordinação jurídica, aos meios pessoais e diretos de comando, controle e supervisão do trabalho alheio (NR) (Grifo nosso. Cf. Lei № 12551 de 15 de dezembro de 2011).
\end{abstract}

Em dezembro de 2016, houve uma nova deliberação na legislação que passou a definir como seria a relação trabalhista no modelo de home office, tanto as obrigações por parte da organização, como por parte do funcionário, o que minimizou os receios gerando um crescimento na implementação do método no país.

De acordo com uma pesquisa realizada pela SAP consultoria, abrangendo 200 empresas que atuam no Brasil, 36\% delas permitem o trabalho remoto, e desse grupo, $42 \%$ já formalizaram a prática, o que nos mostra a expansão do trabalho remoto no Brasil. 
Nesse estudo, analisaremos os benefícios fornecidos pela implementação do trabalho remoto na área de Tecnologia da Informação da empresa Furnas, buscando responder ao seguinte questionamento: $\mathbf{A}$ adoção do trabalho remoto pode aumentar a produtividade de uma organização?

\subsection{Objetivo do estudo}

O presente trabalho de conclusão de curso tem por objetivo analisar o trabalho remoto e seus benefícios após implementação na empresa Furnas, baseado em índices de produtividade. E com base nesses dados, identificarmos a importância ou não da implementação do método na referida organização.

\subsection{Objetivos intermediários do estudo}

Para se atingir o objetivo final proposto, esse estudo tem como objetivos intermediários a serem alcançados:

$\checkmark$ Identificar modelo de trabalho remoto adotado em Furnas

Identificação do modelo de trabalho remoto adotado pela empresa Furnas, no que tange metas, periodicidade, formas de fiscalização e principalmente índices produtivos.

$\checkmark$ Mensurar índices de produtividade após adoção do trabalho remoto Identificação dos índices de produtividade adotados após a inclusão do modelo de trabalho remoto, para que seja possível a comparação com os utilizados antes da adoção, visando identificar mudanças na produtividade corporativa.

$\checkmark$ Comparar índices e apurar resultados

Apuração dos resultados obtidos com a pesquisa, a partir da comparação dos índices utilizados antes e após a implementação do método na área de Tecnologia da Informação e responder a situação problema.

$\checkmark$ Propor melhorias

Por fim, propor revisões e melhorias tanto no estudo que realizamos, quanto nos estudos já existentes sobre o tema. 


\subsection{Delimitação e foco do estudo}

Este estudo volta-se mais especificamente para abordar questão do ganho ou perda de produtividade acarretada pela implementação do trabalho remoto na empresa Furnas.

Primeiramente, definimos o universo de pesquisa que utilizaremos.

Escolhemos como foco do estudo a empresa FURNAS, empresa de economia mista, subsidiária da Eletrobrás, vinculada ao Ministério de Minas e Energia e que mantém e opera um sistema por onde passa cerca de $40 \%$ da energia do Brasil. Hoje a empresa atende a 15 estados, mas nos restringimos a estudar apenas a sede da empresa, sediada na Rua Real Grandeza, 219, Botafogo, Rio de Janeiro.

Para que o Trabalho remoto se faça possível, são necessárias ferramentas tecnológicas, tanto para a realização da tarefa por parte dos funcionários, quanto para o controle por parte dos gestores, e em função disso, decidiu-se realizar a pesquisa especificamente com a área de Tecnologia da Informação, não só pela familiaridade com as ferramentas, mas também por possuir atividades e tarefas possíveis de serem realizadas remotamente.

Foram selecionados em conjunto com os gerentes alguns funcionários da referida área, funcionários esses que se enquadrem nos perfis (importante reforçar que o trabalho remoto não é para todos), e que exerçam atividades que segundo os gerentes são cabíveis de execução remota.

Importante ressaltar que nos basearemos em metas e índices e não em controle de local ou horário a cumprir, a ideia do estudo é completamente inversa, foi dado liberdade e flexibilidade de horário e local para os funcionários buscando perceber melhora ou piora na execução de suas tarefas.

Não delimitaremos também local físico para a execução das tarefas, sendo assim, não se restringe ao domicílio o trabalho remoto, sendo de livre escolha do participante, local ou horário que buscará atingir as metas previstas anteriormente.

\subsection{Justificativa e relevância do estudo}

Visando a evolução das estruturas formais de trabalho, tem como sua principal importância apresentar por que se deve ou não introduzir o home office 
em sua empresa tendo como base, parâmetros relevantes que constatem a eficiência do método estudado.

Por se tratar de um tema que ganhou visibilidade recentemente, este método de trabalho trás consigo alguns receios, tanto por parte da organização quanto por parte dos funcionários, receios esses que pretendemos minimizar com as informações apresentadas nesse estudo.

Primeiramente, olhando pelo ponto de vista da organização, buscaremos produzir informações referentes à redução de custos com transporte, alimentação e instalações, ganhos de produtividade, redução de desperdício de tempo e criação de motivação para os funcionários. Informações essas primordiais para embasar a implementação do método na organização estudada e futuramente nas demais organizações.

Sob o ponto de vista do funcionário, investigaremos o aumento da autonomia na administração do tempo, melhora de desempenho, redução do tempo de locomoção, mais tempo para atividades pessoais. Esse equilíbrio entre trabalho e lado pessoal, gera motivação e confiança, e com isso, mais produtividade.

Por fim, mas não menos importante, analisaremos a relevância do estudo para a sociedade, onde reduzindo a necessidade de deslocamento diário dos funcionários, reduzimos a quantidade de veículos na rua, e por consequência o congestionamento nas grandes capitais, com isso, haverá uma redução na quantidade de $\mathrm{CO} 2$ que é enviado para a atmosfera.

Portanto, independente do público, nota-se a relevância e a necessidade de ser realizado tal estudo, uma vez que o trabalho remoto já é realidade e vem se tornando tendência com o passar dos anos, percebe-se a necessidade de embasamento teórico e prático para a implementação do método nas grandes organizações. 


\section{Revisão de literatura}

Neste capítulo são apresentados e discutidos aspectos conceituais e estudos relacionados ao tema e estudo em investigação que serviu de base para a análise realizada.

Esta seção está dividida em cinco partes e abordam, respectivamente, a questão do trabalho e tecnologia na contemporaneidade, trabalho remoto, comportamento organizacional, produtividade e absenteísmo para contextualizar o problema de estudo ganho ou perda de produtividade com a implementação do modelo de trabalho remoto, se baseando em diversos autores renomados relacionados aos temas citados.

\subsection{Trabalho e Tecnologia na Contemporaneidade}

Embasamo-nos nas visões dos autores Bauman (1999;2001), Sennett (2006) e Castells (1999), que vêem o trabalho em constante transformação, se tornando cada vez mais flexível e incorporando características trazidas pelas evoluções tecnológicas, situação denominada por Bauman de "modernidade líquida", pelo seu caráter informe, volátil, fluido e móvel.

Nos últimos anos, observamos diversas alterações econômicas e sociais, o que gerou mudanças nos mercados de trabalho. Entre elas, podemos citar o envolvimento cada vez maior dos funcionários com as organizações, gerando laços parecidos com os que percebemos em relações religiosas, como os fanáticos fiéis, além da flexibilidade no trabalho ter se tornado ponto crucial na maioria das organizações que buscam ser referências no mercado.

Se pensarmos na Idade Moderna, no século XVII, o trabalho era considerado uma atividade sem valor, restrita aos escravos, ideia que mudou com o surgimento da burguesia, que passou a se dedicar ao comércio. Com os avanços científicos, o início do capitalismo e todas as alterações sociais acarretadas por ele, consolidam o trabalho na sociedade.

Com a Revolução Industrial em XVIII, inicia-se a mecanização do trabalho, inspirado no modelo de gestão do trabalho Taylorista, que prioriza o seguimento de regras estipuladas pelos burocratas por parte dos trabalhadores. 
Esses modelos de gestão foram se transformando através dos anos, e incorporando aspectos das alterações sofridas pelos meios sociais e econômicos, sendo cada vez mais priorizado o aumento da produtividade e a abertura de mercado.

Atualmente a palavra de ordem nas grandes organizações é o comprometimento organizacional, tendo em vista que, as empresas buscam posturas participativas, envolvendo assim o funcionário nas decisões organizacionais, gerando um investimento afetivo por parte deles, uma vez que o trabalhador passa a entender a importância de sua tarefa em um todo, e com isso o trabalho passa a ganhar uma conotação mais positiva e motivadora.

Para Castells (1999) diversos fatores agilizaram as mudanças nos processos de trabalho. Na década de 90, as tecnologias sofreram uma intensa transformação, tornando-se mais acessível e possibilitando sua utilização por uma maior parte da sociedade, o que antes era restrito a alguns de melhor situação financeira. Além disso, com os avanços tecnológicos, as organizações globais precisam travar uma espécie de corrida tecnológica, o que acarretou uma nova forma de agir por parte das empresas, muitas vezes baseadas em atuação em redes.

Com essas alterações no modo de agir, as organizações perceberam a necessidade de se automatizar, o que possibilitou que as mesmas possuíssem sistemas integrados através de uma rede interativa onde toda a comunicação e interação fossem feitas diretamente por ela.

A partir daí os sistemas automotivos se tornaram parte central das organizações, possibilitando a realização de tarefas em lugares distintos por meio de uma rede central. Castells previa ainda uma nova automação por parte das organizações, os chamados "escritórios móveis" onde trabalhadores exerceriam suas funções a partir de dispositivos de processamento e transmissão de informações.

No passado, o trabalho era rotineiro, e previsível, porém, atualmente, há a necessidade cada dia maior de uma flexibilização do mesmo, as organizações buscam funcionários acostumados e preparados às mudanças que constantemente ocorrem nos mercados de trabalho. 
práticas de flexibilidade, porém, concentram-se mais nas forças que dobram pessoas (SENNETT, 2006, p.53).

As estruturas de trabalho antes adotadas como padrão, sofreram alterações, especialmente na ideia de tempo e espaço, antes previsíveis, hoje se encontram com uma conotação bastante ampla, tendo em vista que atualmente, mesmo distantes das organizações, os funcionários conseguem estar ligados a elas através de computadores ou celulares, estando sempre disponíveis.

O sucesso de uma empresa não se faz a partir do controle de tempo e espaço, mas sim pelo resultado do cumprimento de metas e objetivos. (SENNET 2005)

Atualmente, é obrigatório que o funcionário esteja preparado para se adequar as mudanças nos mercados de trabalho e principalmente acompanhar 0 ritmo das mesmas. Segundo SENNET (2005, p. 9), esta ideia trás um novo sentido para o trabalho:

\footnotetext{
Essa ênfase na flexibilidade está mudando o próprio significado do trabalho, e também as palavras que empregamos para ele. "Carreira", por exemplo, significa originalmente, na língua inglesa, uma estrada para carruagens, e, como acabou sendo aplicada ao trabalho, um canal para as atividades econômicas de alguém durante a vida inteira. O capitalismo flexível bloqueou a estrada reta da carreira, desviando de repente os empregados de um tipo de trabalho para outro.
}

A ideia de carreira hoje em dia, saiu de foco, dando espaço à ideia de empregabilidade. Com um mercado cada vez mais intenso, a velocidade com que as empresas precisam se transformar cresce bastante também, logo, independente das qualificações possuídas pelo funcionário, caso ele não se adeque será facilmente removido e substituído. Apesar das mudanças no pensamento, o trabalho continua sendo parte vital da sociedade e central na vida de qualquer indivíduo, e em função disso, independente de qual seja a mudança, o funcionário precisa estar disposto a se adequar.

Um método percebido pelas organizações para melhor adequar seus funcionários e ao mesmo tempo buscar a produtividade desejada é o chamado trabalho remoto, conceito que apresentaremos a seguir.

\subsection{Trabalho Remoto}

Primeiramente, importante ressaltar que faremos o uso do termo Trabalho Remoto ou home office, porém, o mesmo também é denominado de 
Teletrabalho, Telework. Termos usados para definir o trabalho que é realizado fora do espaço físico da organização através de instrumentos tecnológicos.

A primeira aparição, não do termo, mas da ideia foi em 1857, quando J. Edgar Thompson, da empresa Penn Railroad usou seu próprio sistema de telegrafia para monitorar e controlar funcionários e equipamentos nos canteiros de obras de uma das construções da empresa. Apesar de na época o fato não ser denominado de Trabalho Remoto, foi a primeira vez que a ideia de controle da produtividade ser realizada à distância foi utilizada.

Apesar de não ser um assunto atual, nos últimos anos o Trabalho Remoto vem ganhando força entre as organizações mundiais, pois trás consigo uma alternativa para as estruturas atuais de trabalho e um grande gerador de vantagem competitiva visando adequação aos mercados instáveis atuais.

O home office visa flexibilizar as estruturas organizacionais, buscando novas idéias de tempo, local e comunicação, e se tornou possível através das inovações tecnológicas.

Apesar de algumas empresas terem utilizado o método a partir da década de 70 , era vista pela maioria como utopia, visão essa que vem se alterando a partir das facilidades trazidas pela era da conectividade. Atualmente, é possível pessoas das mais variadas localizações interagirem por meio de instrumentos tecnológicos, e seguindo essa idéia, hoje é possível que o funcionário exerça a mesma função exercida na empresa física a partir do seu domicílio, sendo necessários apenas alguns instrumentos como computador e software utilizado pela empresa.

Apesar de o termo vir ganhando força, ainda há muita dificuldade para defini-lo, pois, os diversos autores de estudos sobre o tema divergem em vários aspectos que vão desde periodicidade de trabalho, até a forma de remuneração.

Para Jack Nilles (Telework, 1997), o trabalho remoto é conceituado como o uso de telecomunicações em atividades trabalhistas divergentes das levadas como padrão, e que tem como trabalhadores remotos pessoas que usam a telecomunicação para superar as barreiras impostas pelo tempo e pelo espaço.

O telecommutingGuide (1999) define o trabalho remoto como a seleção de funcionários que são permitidos exercer suas funções organizacionais de seu domicílio ou outro local que não seja a empresa onde atua.

Para Mello (1999) trabalho remoto é toda função exercida independente de espaço geográfico, sendo utilizada tecnologia para a mesma.

A SOBRATT (Sociedade Brasileira de Teletrabalho e Teleatividade) diz que: 
Teletrabalho é todo e qualquer trabalho realizado à distância (tele), ou seja, dora do local tradicional de trabalho (escritório da empresa), com a utilização da tecnologia da informação e da comunicação, ou mais especificamente, com computadores, telefonia fixa e celular e toda tecnologia que permita trabalhar em qualquer lugar e transmitir informações, arquivos de texto, imagem ou som relacionados à atividade laboral.

Independente da definição, uma ideia é central, a flexibilidade, tanto de horário, quanto de local, salário, contrato, qualificação e qualquer outro aspecto que integra as relações trabalhistas. As formas de contratação também vêm sofrendo alterações, deixando de ser duradouras e adotando um perfil mais pontual, existindo pessoas contratadas apenas para atividades específicas e por um período de tempo também específico.

Podemos resumir os trabalhos flexíveis atuais da seguinte forma:

$\checkmark$ Trabalho Remoto (Home Office): Forma mais conhecida de trabalho remoto. A empresa disponibiliza laptop, conexão com internet e softwares utilizados pela organização, além de toda estrutura necessária para a realização da tarefa, como mesas, cadeiras e etc. Pode ser em tempo integral ou parcial, dependendo da cultura da empresa.

$\checkmark$ Trabalho Autônomo: 0 chamado freelancer. Profissionais especializados, contratados para exercer atividades específicas e sem vínculo empregatício, que atuam remotamente apresentando a empresa apenas os resultados obtidos.

$\checkmark$ Shared centers: Denominados também de centros compartilhados. Grupos de trabalhadores especializados nas mais diversas áreas, que prestam serviços a filiais ou clientes em pontos diversos da geografia mundial.

$\checkmark$ Trabalho Móvel: Normalmente utilizado por funcionários da área de vendas, os mesmos não possuem espaço físico na empresa, como mesa, cadeira, porém, possuem seu laptop e executam parte de suas tarefas de forma remota comparecendo poucas vezes a empresa.

$\checkmark$ Centros satélites: Escritórios menores da empresa, pelos quais os funcionários podem optar caso sejam mais pertos de suas residências. 
Apesar da existência de diversas modalidades, nesse trabalho nos restringimos ao Trabalho Remoto (Home Office).

Segundo dados da Organização Internacional do Trabalho, Alemanha, Argentina, Bélgica, Canadá, Estados Unidos, Portugal e Brasil, já adotam o modelo de home office de forma consistente. Nos Estados Unidos está nova estrutura de trabalho já atinge praticamente todas as grandes empresas do país, sendo constatado pela revista Fortune (The Best PlacetoWork) que $80 \%$ das 100 "melhores organizações para se trabalhar" do país já utilizam o modelo de home office no seu dia-a-dia.

No Brasil, uma das grandes dificuldades para a implementação do Trabalho Remoto era a falta de definição do mesmo, situação que causava uma grande preocupação por parte das organizações para a adoção do método.

Em 15 de dezembro de 2011, foi deliberado o artigo 6으 da CLT que equipara os trabalhadores remotos aos demais trabalhadores assalariados.

Art. 6․ Não se distingue entre 0 trabalho realizado no estabelecimento do empregador, o executado no domicílio do empregado e o realizado a distância desde que estejam caracterizados os pressupostos da relação de emprego. Parágrafo único. Os meios telemáticos e informatizados de comando, controle e supervisão se equiparam, para fins de subordinação jurídica, aos meios pessoais e diretos de comando, controle e supervisão do trabalho alheio.

Atualmente já existe a Lei $n^{0} 13.467$ na CLT, que define o Trabalho Remoto, o que diminuiu o receio por parte das organizações e impulsionou o crescimento do mercado no Brasil. Segue abaixo o texto oficial da Lei.

\section{CAPÍTULO II-A DO TELETRABALHO}

'Art. 75-A. A prestação de serviços pelo empregado em regime de teletrabalho observará o disposto neste Capítulo.'

'Art. 75-B. Considera-se teletrabalho a prestação de serviços preponderantemente fora das dependências do empregador, com a utilização de tecnologias de informação e de comunicação que, por sua natureza, não se constituam como trabalho externo.

Parágrafo único. O comparecimento às dependências do empregador para a realização de atividades específicas que exijam a presença do empregado no estabelecimento não $\begin{array}{llll}\text { descaracteriza } & 0 & \text { regime de teletrabalho.' }\end{array}$

'Art. 75-C. A prestação de serviços na modalidade de teletrabalho deverá constar expressamente do contrato individual de trabalho, que especificará as atividades que serão realizadas pelo empregado. 
$\S 1$ 1 Poderá ser realizada a alteração entre regime presencial e de teletrabalho desde que haja mútuo acordo entre as partes, registrado em aditivo contratual.

$\S 2^{\circ}$ Poderá ser realizada a alteração do regime de teletrabalho para o presencial por determinação do empregador, garantido prazo de transição mínimo de quinze dias, com correspondente registro em aditivo contratual.'

'Art. 75-D. As disposições relativas à responsabilidade pela aquisição, manutenção ou fornecimento dos equipamentos tecnológicos e da infraestrutura necessária e adequada à prestação do trabalho remoto, bem como ao reembolso de despesas arcadas pelo empregado, serão previstas em contrato escrito.

Parágrafo único. As utilidades mencionadas no caput deste artigo não integram a remuneração do empregado.'

'Art. 75-E. O empregador deverá instruir os empregados, de maneira expressa e ostensiva, quanto às precauções a tomar a fim de evitar doenças e acidentes de trabalho.

Parágrafo único. $\mathrm{O}$ empregado deverá assinar termo de responsabilidade comprometendo-se a seguir as instruções fornecidas pelo empregador."'

"Art. 134.

$\S 1$ Desde que haja concordância do empregado, as férias poderão ser usufruídas em até três períodos, sendo que um deles não poderá ser inferior a quatorze dias corridos e os demais não poderão ser inferiores a cinco dias corridos, cada um.

(Revogado).

$\S 3$ ํ É vedado o início das férias no período de dois dias que antecede feriado ou dia de repouso semanal remunerado." $(\mathrm{NR})$

A SOBRATT estima que em 2005 existiam apenas 500 mil trabalhadores remotos no país, já em 2008 esse número subiu para 10 milhões e 600 mil trabalhadores remotos, sendo possível observar o crescimento do modelo no país.

Outro ponto que gera muita discussão sobre o tema é a questão dos perfis de trabalho. O home office infelizmente, não pode ser exercido por todos os profissionais, pois possui algumas restrições. Existem tarefas que necessitam do comparecimento do funcionário a empresa diariamente, ocorrendo quando as ferramentas que ele necessita não podem ser retiradas do espaço físico da organização. Além da restrição de atividade, existe também a de perfil, como explica Reis (2007), o colaborador passa a ter que desenvolver uma estrutura para gerir seu tempo, conciliando suas horas de trabalho e as horas para suas 
demais atividades pessoais, sendo necessário a determinação de um ponto de equilíbrio para que possa buscar a excelência em todas as áreas de sua vida.

A literatura existente sobre o tema busca apresentar em sua maioria os pontos positivos da adoção do método. Entre eles podemos citar a melhoria na qualidade de vida, reduzindo stress, causado pela locomoção diária e os congestionamentos nas grandes capitais, a diminuição dos riscos de segurança, levando em consideração o aumento dos índices de criminalidade em nossa cidade, entre outros.

Um ponto importante apresentado por uma pesquisa realizada pela SBCoaching, em 2015, é o tempo desperdiçado em situações pontuais como café ou redes sociais, tempo esse que também pode ser minimizado através do trabalho remoto.

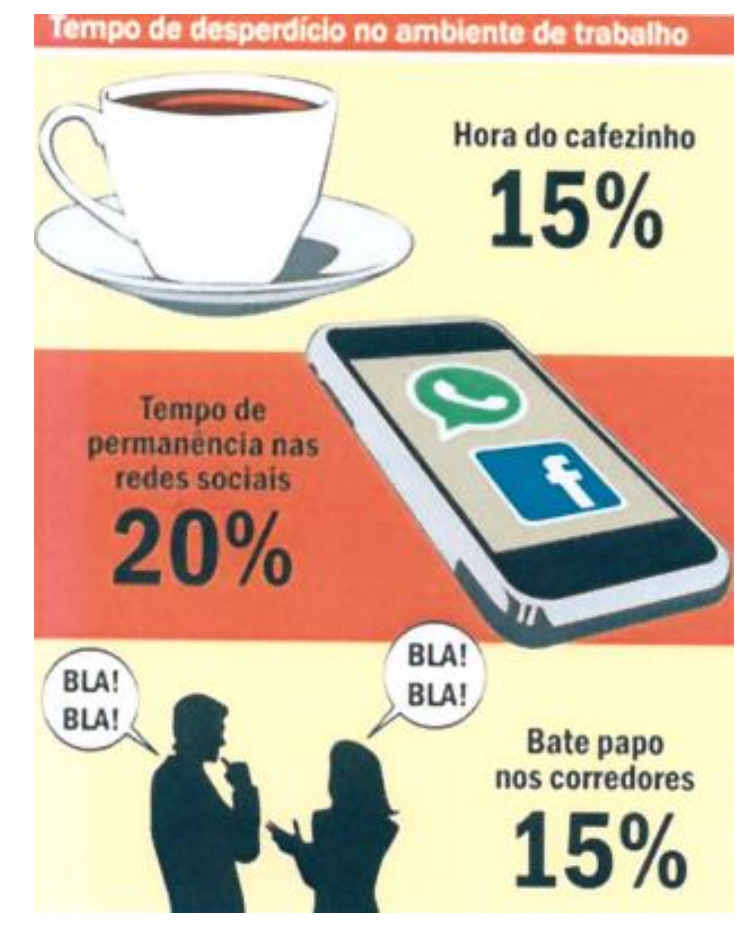

Figura 1: Pesquisa sobre desperdício de tempo no trabalho (SBCoaching, 2015)

Além dos aspectos citados, existe um fator crucial para as organizações, a redução dos custos (transporte, instalações, café e etc). Como exemplo podemos citar um funcionário que mora em Teresópolis e trabalha na empresa estudada, onde seu gasto com transporte é de $R \$ 80,00 /$ dia, ou seja, $R \$$ 1782,00/mês, e esse funcionário exercendo sua função em domicílio, resultaria numa redução de $36,5 \% /$ mês desse custo. 
Porém, como em todo método existem implicações. Naturalmente, exercendo a função em domicílio o funcionário acaba trabalhando tempo a mais do que trabalharia na empresa, o que geraria horas extras, existindo muita dificuldade de serem contabilizadas nesse método. Outro ponto importante é que o trabalho remoto exige bastante autocontrole, muita disciplina e grande capacidade de gerenciamento de tempo. Autocontrole para conseguir lidar com tentações como acordar tarde, disciplina na hora de começar e terminar o expediente e o gerenciamento do tempo para que as tarefas possam acontecer de acordo com os prazos. Além disso, algo que é unanimidade quando o assunto é Trabalho Remoto é um possível isolamento social e distrações domésticas, porém, felizmente os desafios gerados pelo trabalho remoto são de fácil solução, bastam pequenas mudanças na cultura da empresa e no comportamento organizacional da mesma.

\subsection{Comportamento Organizacional}

Como já dito anteriormente, o trabalho se tornou parte crucial da sociedade e da vida de cada indivíduo. Passamos a maior parte de nossas vidas dentro de organizações, independentemente se profissional ou pessoalmente, estamos sempre em contato com elas, e em razão disso, é fundamental compreendermos seu comportamento e funcionamento.

As mudanças nas estruturas de trabalho, acarretadas pela globalização geraram transformações em vários aspectos do mesmo, como por exemplo, na força de trabalho, na expectativa dos clientes, etc.

Independente da profissão que escolha, será primordial conhecer o comportamento organizacional da empresa que está inserido para que possa alcançar o sucesso dentro da mesma, pois, apesar de qualquer habilidade técnica e teórica, são as habilidades interpessoais que indicam o êxito ou fracasso de qualquer projeto organizacional.

Comportamento Organizacional, também conhecido como CO refere-se ao estudo do comportamento de grupos ou indivíduos que integram organizações inseridas em mercados cada vez mais instáveis, mutáveis e competitivos, ou seja, a interação entre a organização e seu ambiente externo.

Um dos desafios para a compreensão do CO é o fato de haver aspectos superficiais, fáceis de serem percebidos como estratégias da organização, objetivos, políticas, entre outros, porém, também existem alguns intrínsecos e de difícil percepção como as atitudes individuais, normas grupais, interações 
interpessoais, que apesar de imperceptíveis, tem participação direta no funcionamento de toda organização.

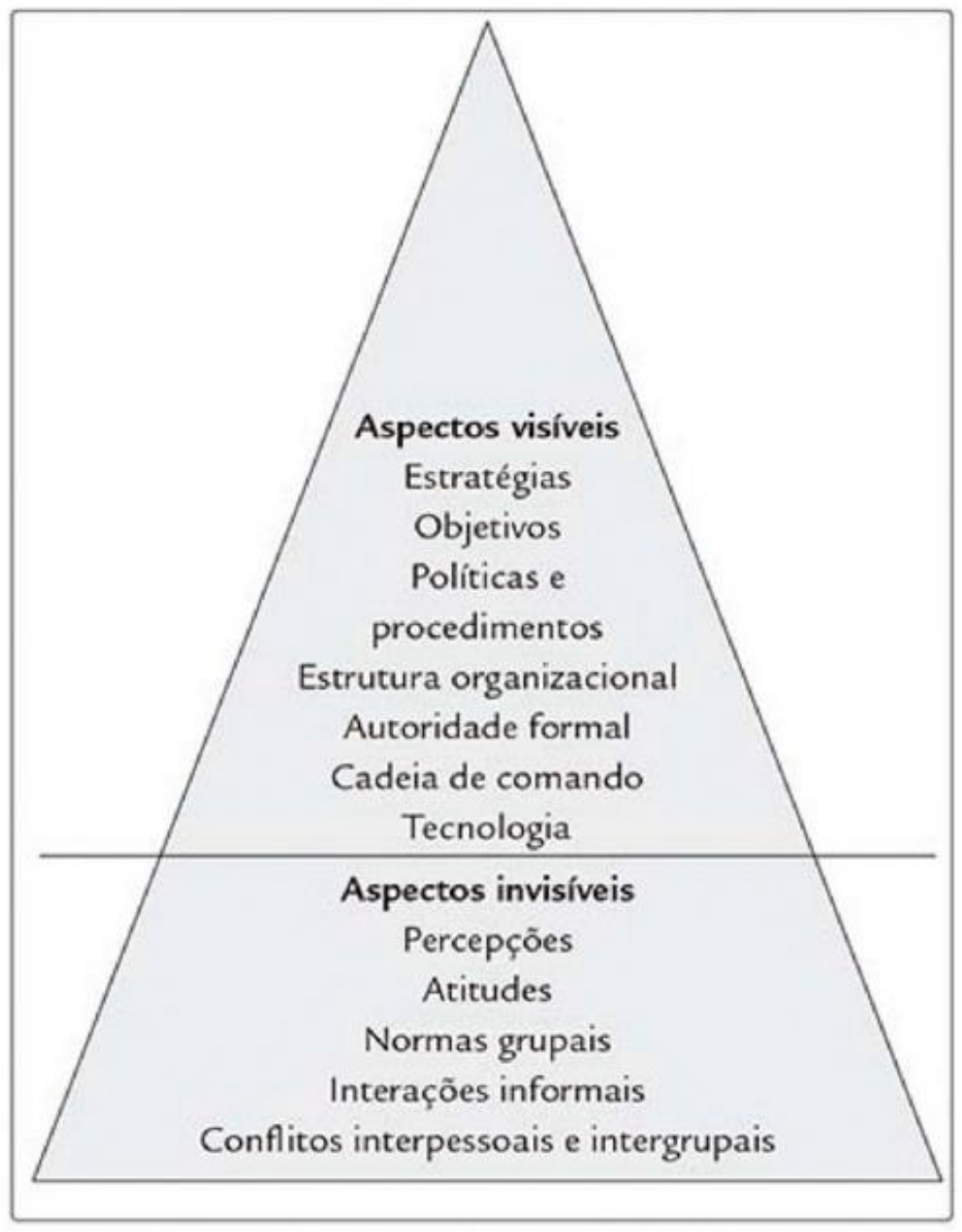

Figura 2: Pirâmide dos aspectos visíveis e invisíveis do comportamento organizacional (Chiavenato, 2014)

Segundo Chiavenato, o CO tem algumas características relevantes, e mesmo não sendo uma ciência propriamente dita, é uma área de estudo vital para qualquer organização. As principais são:

1. CO é uma disciplina científica aplicada: O CO está ligado a questões práticas no sentido de ajudar pessoas e organizações a alcançar níveis elevados de desempenho que nunca foram atingidos antes. Sua aplicabilidade está em buscar simultaneamente de aumentar a satisfação das pessoas no trabalho e elevar os padrões de competitividade, sustentabilidade e de sucesso da organização. 
2. CO adota uma abordagem contingencial: O CO procura identificar as diferentes situações organizacionais para que se possa lidar com elas e extrair seu máximo proveito. O CO utiliza a abordagem situacional, já que não existe uma única e exclusiva maneira de lidar com as organizações e com as pessoas que nelas trabalham. Tudo depende das circunstâncias e nada é fixo ou imutável.

3. CO utiliza métodos científicos: O CO utiliza a abordagem situacional, já que não existe uma única e exclusiva maneira de lidar com as organizações e com as pessoas que nela trabalham. Tudo depende das circunstâncias e nada é fixo ou imutável.

4. CO ajuda a lidar com as pessoas nas organizações: As organizações são entidades vivas e com uma incrível dinamismo. Mais do que isso, são entidades sociais, pois são constituídas de pessoas. O objetivo básico do $\mathrm{CO}$ é ajudas as pessoas e organizações a se entenderem cada vez melhor. $\mathrm{O} \mathrm{CO}$ é fundamental para os administradores que dirigem organizações ou unidades delas, assim como é indispensável para toda e qualquer pessoa que pretenda ser bem sucedida em sua atividade com as organizações, dentro ou fora delas.

5. O CO recebe contribuições: Tem influência de várias ciências comportamentais, como:

5.1. Ciências políticas: conceitos sobre poder, conflito e política organizacional, etc.

5.2. Antropologia - conceitos sobre cultura organizacional, análise cultural, valores e atitudes, etc.

5.3. Psicologia: conceitos sobre diferenças individuais, personalidade, sensação, percepção, motivação, aprendizagem, etc.

5.4. Psicologia social: conceitos sobre grupo, dinâmica de grupo, interação, liderança, comunicação, atitudes, tomada de decisão grupal, etc. 5.5. Sociologia: status, prestígio, poder e conflito, etc.

5.6. Sociologia organizacional: teoria organizacional, dinâmica organizacional, etc.

6. CO está intimamente relacionado a vários campos de estudo: teoria das organizações (TO), desenvolvimento organizacional (DO) e gestão de pessoas (GP) ou administração de recursos humanos (ARH). Em comparação com essas disciplinas, o CO tende a ser teoricamente orientado para o nível micro de análise, na medida em que utiliza as 
abordagens teóricas das ciências comportamentais para focalizar principalmente o comportamento individual e grupal nas organizações. No nível macro, o CO recebe enorme contribuição da Administração, principalmente no que tange à estratégia organizacional e à administração das organizações.

Logo, segundo Chiavenato, um dos principais estudiosos do tema, o CO pode ser definido como, "a compreensão, a predição e a gestão do comportamento humano na organização".

Como já citado anteriormente nesse estudo, com o mercado cada vez mais volátil e mutável, as empresas mudaram seus perfis de atuação, sendo necessário que os funcionários estejam engajados com os objetivos da organização e preparados para se adaptar à mudança, e pensando nisso, Chiavenato aponta como as principais variáveis da atuação das pessoas na organização o desempenho, o engajamento, a fidelidade, a satisfação no trabalho e a cidadania organizacional.

As variáveis principais dão origem às variáveis intermediárias, que são adaptabilidade e flexibilidade, a qualidade, a inovação, a satisfação do cliente e a produtividade. Em nosso estudo, levaremos como base para nossa pesquisa e para conclusão de nossos resultados os índices de produtividade, conceito que será tratado e melhor explorado em seguida.

\subsection{Produtividade}

Com as constantes mudanças no mercado, as empresas se tornaram cada vez mais globais, e buscam sempre se posicionarem na liderança dos mercados em que atuam, focando no atendimento ao cliente, nas boas práticas de gestão, na qualidade dos serviços e produtos, mas certamente o ponto mais importante é a produtividade, pois é ela quem dita o ritmo do mercado e posiciona determinada empresa no mesmo.

A ideia de produtividade como é pensada hoje teve suas primeiras definições no século $X X$, porém, a noção de produtividade como avanço econômico e técnico já era vigente desde o século XIX.

Segundo Neto (apud SATT; CRISTELLO, 2009) a palavra produtividade pode estar inserida em diversas situações, porém, independente de qual, o objetivo comum é estar ligada ao rendimento da empresa, rendimento esse 
atrelado a diversos fatores. Ela depende diretamente do desenvolvimento de recursos humanos como, interesse, técnica, gerenciamento, consciência entre outros.

Produtividade, associada à qualidade, tecnologia e recursos humanos, são os indicadores principais da performance produtiva. Após a segunda guerra mundial, houve um avanço do aspecto tecnológico, sendo, mais tarde, assimilado também o conceito de qualidade. Para Deming (1990), a qualidade é o caminho para a revolução da administração buscando a competitividade do mercado, e que só é possível através de modificações nas estruturas trabalhistas.

Para que a empresa se porte de maneira competitiva, é necessário que ela possua funcionários engajados e motivados, motivação essa que é proporcionada pelos gestores, através de remunerações e políticas organizacionais. Quanto maior a motivação do funcionário, melhor será a qualidade na execução de sua tarefa.

Quanto maior a qualidade na execução da tarefa, maior a produtividade da organização, porém, é necessária a medição para garantir que essa alteração esteja trazendo resultados pertinentes no desempenho da organização como um todo.

Segundo Tirone (1993), os principais indicadores estão atrelados à participação no mercado e desenvolvimento de novos mercados, desempenho de produtos e serviços, satisfação dos clientes, desempenho operacional e financeiro, de fornecedores, de recursos humanos, no espírito comunitário e na responsabilidade pública.

A gestão dos recursos humanos é um dos grandes desafios organizacionais atualmente, pois, como já citado, os mercados estão em constante transformação, sendo necessários funcionários também propícios a alterações, o que torna árduo o processo de definição de perfis e qualificações para a contratação.

Atualmente, as organizações têm trocado a ideia de "corações e máquinas" por "corações e mentes", de acordo com as alterações nas estruturas de trabalho e com o aumento da importância do capital humano visando essas adequações.

Cada vez mais as organizações buscam compreender a natureza dos indivíduos e os aspectos culturais de cada grupo, preocupação que resgata o interesse do homem pelo trabalho, e consequentemente uma melhora na qualidade gerando uma maior produtividade por parte dos funcionários. 
Portanto, possuímos duas formas de apresentar resultados quanto à produtividade, o raciocínio linear e o sistêmico. No linear, levamos em consideração apenas aspectos quantitativos, podendo apontar desempenho simplesmente baseados em valores financeiros. Já no raciocínio sistêmico, levamos em consideração, além de valores mensuráveis, outros aspectos como motivação, desempenho social, sinergia na organização, entre outros.

Visando a melhor combinação de ambos os aspectos, buscando alcançar o melhor desempenho linear em conjunto com o sistêmico, o home office seria uma alternativa para a estrutura formal de trabalho.

Para Moller (2012) as empresas que passaram a adotar o home office, tiveram alterações positivas nas suas estruturas, pois, pode ser uma alternativa para superar barreiras físicas que poderiam dificultar a realização da função de forma física, possibilitando também a busca por mercados alternativos, não havendo mais as barreiras geográficas. Nas próprias palavras do autor:

Não há o que se questionar que esta modalidade de prestação de serviço acarreta em benefícios para o empregador, visto que seu surgimento se deu a partir de uma adaptação das relações de trabalho às exigências que as próprias empresas padronizaram diante de uma nova estrutura de mercado criada.

Além dos aspectos já citado, outro ponto fundamental ligado à produtividade, é o absenteísmo, funcionário motivado tende a ter uma taxa menor, pois o trabalho deixa de ser tratado como algo sofrível e passa a ser visto como uma extensão de sua vida pessoal.

\subsection{Absenteísmo}

O trabalho trás com ele diversos fatores, sendo parte central da vida dos indivíduos e um dos principais meios de formação de identidade e status. Além dos benefícios positivos, o trabalho pode causar também efeitos negativos nos indivíduos, como por exemplo, o estresse, doença que atinge diretamente as grandes organizações.

Além da competitividade do mercado cada vez maior, o que acarreta o estresse, outras doenças associadas às condições de trabalho podem acarretar diversos problemas como, insatisfação, ansiedade, esgotamento e até a depressão.

Segundo Fernandes (2011), Ferreira (2012), Martinato (2010) e Umann (2011), o Absenteísmo é um problema administrativo complexo, acarretado pela 
competitividade inerente do mercado atual ligado a insegurança e falta de condições para a execução das tarefas na organização.

Entre as situações causadas por essas doenças, podemos citar o absenteísmo laboral. Podemos defini-lo, de acordo com Cucolo e Perruca (2008), como falta de assiduidade ao trabalho ou a outros compromissos sociais.

Podemos dividi-los em:

$\checkmark$ Absenteísmo voluntário - inclui ausências por razões pessoais do funcionário.

$\checkmark$ Absenteísmo por doença - inclui ausências por doenças ou procedimentos médicos não acarretados diretamente pelo trabalho.

$\checkmark$ Absenteísmo legal - inclui ausências justificadas pela legislação, como parto ou doação de sangue.

$\checkmark$ Absenteísmo compulsório - inclui ausências devido a suspensão por parte da organização, prisão, entre outros.

Para autores como Porto e Paula (2010) ou Fernandes (2011), o Absenteísmo é um fenômeno multifatorial, ao qual não existe uma razão específica, mas sim, um conjunto de fatores que levam a ele.

Segundo Umann (2011), o absenteísmo é um indicador crucial para a definição das condições de trabalho, da política de recursos humanos, do serviço de saúde ocupacional da empresa, e, principalmente da produtividade, pois, um funcionário absenteísta tende a ter um nível produtivo abaixo do esperado.

Existem alguns fatores organizacionais que podem acarretar tal fenômeno, entre eles podemos citar:

$\checkmark$ Fatores sociais e culturais do trabalho

$\checkmark$ Fatores geográficos

$\checkmark$ Doenças

$\checkmark$ Fatores ambientais

$\checkmark$ Características individuais e grupais de personalidade e comportamento

A partir disto, autores como Murcho e Jesus (2007) os dividem em fatores organizacionais, individuais e de ambiente de trabalho. Destes três, o que menos é estudado são os individuais, apesar de se corrigidos, terem a capacidade de gerar vantagens competitivas através do capital humano.

O indivíduo, muitas vezes não transparece tal mal-estar, porém, é possível perceber alguns sintomas, tanto físicos, como cognitivos, emocionais e comportamentais, e um estudo mais aprofundado dos mesmos, pode ser importante para futuras pesquisas sobre o tema. 
O absenteísmo é um mal que atinge grande parte das organizações, e muito se dá pelo fato de ser dado pouco valor ao estudo do mesmo, porém, certamente, com a redução do absenteísmo, a produtividade das grandes empresas tende a crescer, e em função disso, trazemos o home office como possibilidade de redução de tal fenômeno, tendo em vista que, mesmo em situações onde o funcionário não pudesse comparecer a empresa, independente do motivo, seria possível a execução de suas tarefas de algum outro local, evitando assim a perda de produtividade, e muitas vezes, gerando até mesmo o acréscimo dela, o que pretendemos demonstrar com nosso estudo. 


\section{Métodos e procedimentos de coleta e de análise de dados do estudo}

Este capítulo pretende informar sobre as diversas decisões a cerca da forma como este estudo foi realizado.

Está dividido em cinco seções que informam, respectivamente, sobre as etapas de coleta de dados do estudo realizado, sobre as fontes de informação selecionadas para coleta de informações neste estudo. Na sequência, informase sobre os processos e instrumentos de coleta de dados realizados em cada etapa, com respectivas justificativas, sobre as formas escolhidas para tratar e analisa os dados coletados e, por fim, sobre as possíveis repercussões que as decisões sobre como realizar o estudo impuseram aos resultados assim obtidos.

\subsection{Etapas de coleta de dados}

Para compreendermos e analisarmos de maneira eficaz o problema decidiu-se por um estudo parcialmente quantitativo e parcialmente qualitativo.

A primeira etapa optou-se por um estudo quantitativo. Quanto aos fins, consistiu em pesquisa exploratória, pois apesar da empresa Furnas ser alvo de diversos estudos tanto na área de tecnologia quanto nas diversas áreas da empresa, não foram percebidos estudos anteriores a respeito do tema. Já quanto aos meios, podemos definir como estudo de campo, bibliográfica e documental. Estudo de campo pela investigação empírica está sendo realizada exatamente no local onde ocorreu o fenômeno que buscamos estudar, bibliográfica, pois para embasarmos nossa pesquisa, utilizamos diversas referências bibliográficas relacionadas aos temas, trabalho e tecnologia na contemporaneidade, trabalho remoto, comportamento organizacional, produtividade e absenteísmo, e documental, pois utilizaremos em nossa investigação documentos internos da empresa.

A segunda etapa optou-se por um estudo qualitativo, pois, quando tratamos o tema absenteísmo, se torna difícil à mensuração de critérios apenas quantitativos para a definição do mesmo. Quanto aos fins, consistiu em pesquisa descritiva, pois levaremos em consideração para determinarmos melhora ou 
piora quanto ao absenteísmo, à percepção dos gestores envolvidos no estudo. Já quanto aos meios, podemos definir como estudo de campo, pois realizamos entrevistas com os gestores envolvidos na implementação do método na empresa.

\subsection{Fontes de informação selecionadas para coleta de dados no estudo}

Foram utilizados como fontes de informação, recursos já existentes sobre o tema como livros, artigos, trabalhos acadêmicos, além de duas etapas de coleta de informações na organização estudada.

A primeira etapa, consistiu na implementação de um projeto piloto que foi denominado Furnas Remote, que visa à adoção do trabalho remoto por parte da área de Tecnologia da Informação da empresa Furnas. Nele foram selecionados seis participantes, que através de um acesso via Virtual Private Network (VPN), teriam acesso ao sistema da empresa, através de um dispositivo remoto de sua residência ou local externo a sede da empresa. Através desse acesso seria possível a mensuração da periodicidade trabalhada pelos mesmos.

Foi solicitado aos gerentes da área envolvida que indicassem funcionários que possuíssem tarefas ou atividades que pudessem ter seu tempo de execução estimado, para assim ser possível a medição da produtividade, definindo esse perfil de funcionário como sendo nosso universo de pesquisa. Com relação aos mesmos, amostragem utilizada é a de tipicidade.

Importante ressaltar que as identidades dos participantes tanto da etapa quantitativa, quanto da etapa qualitativa serão preservadas, sendo utilizados os termos "colaborador x" e "gerente x" onde x equivalerá a um número.

$\mathrm{Na}$ tabela abaixo listamos os participantes e seus cargos: 


\begin{tabular}{|l|l|}
\hline Nome & Cargo \\
\hline Colaborador 1 & Analista de Sistemas \\
\hline Colaborador 2 & Analista de BI \\
\hline Colaborador 3 & Analista de Sistemas \\
\hline Colaborador 4 & Administrador do Windows \\
\hline Colaborador 5 & Administrador de Banco de Dados \\
\hline Colaborador 6 & $\begin{array}{l}\text { Administrador do Ambiente de } \\
\text { Segurança de Rede }\end{array}$ \\
\hline
\end{tabular}

Tabela 1: Participantes do projeto piloto e seus respectivos cargos

Na segunda etapa, após o fim do período de realização do Furnas Remote, buscamos realizar entrevistas com os gestores da área estudada, para juntos buscarmos a percepção dos mesmos sobre o tema absenteísmo. Tendo em vista que diferente da empresa fixa, no trabalho remoto, o que determina ou não se o funcionário está trabalhando é o login na rede via VPN, login esse que não comprova realmente a integralidade do tempo voltado ao exercício da função.

Foram selecionados três gestores, conforme quadro abaixo:

\begin{tabular}{|l|l|}
\hline Gerente 1 & Gerente Substituta \\
\hline Gerente 2 & Gerente de TI \\
\hline Gerente 3 & Gerente Substituta \\
\hline
\end{tabular}

Tabela 2: Gerentes participantes do projeto piloto e seus respectivos cargos

Aqui é importante ressaltar que, o trabalho remoto tem como base a produtividade e não as horas trabalhadas, portanto, para conseguirmos mensurar uma melhora ou piora no que tange o absenteísmo na empresa, questionamos os gerentes envolvidos na implementação quanto a sua percepção sobre o mesmo.

\subsection{Procedimentos e instrumentos de coleta de dados utilizados no estudo}

Na primeira etapa, os selecionados receberam duas planilhas de controle de atividades/tarefas, para que após preenchimento fosse possível coletar os dados da execução das mesmas, visando o alcance das metas prédeterminadas pelos gestores. Por se tratarem de cargos distintos, mensuramos 
produtividade a partir do alcance das metas, metas essas baseadas em horas e não nas atividades propriamente ditas.

Foi determinado que no período de um mês fossem realizados quatro dias de trabalho de forma remota por cada um dos participantes selecionados.

Em função ao acesso via VPN, bastava os funcionários acessarem a rede utilizando login e senha usados por eles na empresa física, e assim, seria possível a mensuração do período utilizado para a realização das tarefas préestabelecidas. A configuração da VPN é simples, são 60 minutos em caso de ociosidade, 240 minutos o tempo de sessão, o que possibilita 4 horas conectados e 10 minutos antes do fim da sessão, surge uma caixa de diálogo de confirmação avisando do mesmo.

Session lifetime

* Idle Timeout:

* Max. Session Length:

× Reminder Tíme:

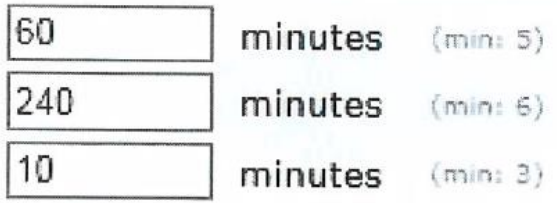

Figura 3: Configuração da VPN

É possível consultar o acesso dos funcionários. Veja:

\begin{tabular}{|c|c|c|c|c|c|c|c|c|c|c|}
\hline Usemame & Realm & Login Time & Logout Time & Duration & Device ID & MAC Address & Auth Result & Compllance & IP Address & Role \\
\hline corplfir21115 & Furnas-Users & Wed Jun 07 14:20:10 2017 & Wed Jun o7 17:55:06 2017 & $3 \mathrm{~h} 34 \mathrm{~m} 56 \mathrm{~s}$ & & & success & compliant & 192.168.3.66 & $\begin{array}{l}\text { Furnas-Users } \\
\text { Terminat } \\
\text { Dispositivos_Apple }\end{array}$ \\
\hline corplff21115 & Furnas-Users & Wed Jun 07 10:28:04 2017 & Wed Jun 07 14:20:15 2017 & $3 \mathrm{~h} 52 \mathrm{~m} \mathrm{11 \textrm {s }}$ & & & Success & Compliant & 192.168.3.66 & $\begin{array}{l}\text { Funras-Usuers } \\
\text { Terminal } \\
\text { Dispositivos Apple }\end{array}$ \\
\hline corplfiz1115 & Furnas-Users & Wed Jun 07 06:23:16 2017 & Wed Jun 07 10:23:42 2017 & 4h $0 \mathrm{~m} 26 \mathrm{~s}$ & & & Success & Not-Assessed & 192.168.3.66 & $\begin{array}{l}\text { Furnas-Users } \\
\text { Terminal } \\
\text { Dispositivos_Apple }\end{array}$ \\
\hline
\end{tabular}

Figura 4: Histórico de acesso na VPN

$\mathrm{Na}$ segunda etapa, foi realizado primeiramente um contato via e-mail com os gestores responsáveis pela área de Tecnologia da Informação, nosso objeto de estudo, descrevendo a dificuldade quanto a mensuração de índices quantitativos de absenteísmo e explicando a busca por índices qualitativos. Os gestores se mostraram dispostos a inferir sobre o tema. Foram estruturados dois questionamentos a respeito do assunto para que fossem respondidos pelos mesmos, conforme abaixo: 
1. Em relação ao tema absenteísmo, na visão dos senhores, após a aplicação do método de trabalho remoto ocorrem a diminuição de tais índices? Justifique.

2. Ainda sobre o tema, a ideia de trabalho remoto está diretamente ligada a produtividade e não tanto a periodicidade, o que pensam sobre isso?

Os questionamentos foram repassados aos gestores via e-mail e respondidos por todos e após as respostas coletadas, além de confirmarmos a pertinência do estudo, enriquecemos a produção do mesmo com as análises realizadas.

\subsection{Formas de tratamento e análise dos dados coletados para o estudo}

$\mathrm{Na}$ primeira etapa as informações coletadas foram tratadas de três maneiras, primeiro a análise e exploração do conteúdo, após isso a organização do material estudado e por fim o tratamento e a interpretação dos resultados.

Primeiramente, organizamos o material, para que assim se tornasse mais simples a compreensão dos resultados, após isso foi realizada uma análise profunda das planilhas fornecidas pelos funcionários, buscando visualizar as metas estipuladas e o período utilizado para a realização das mesmas. E por fim, mensuramos os resultados, equiparando a periodicidade esperada e a entregue pelos funcionários, sendo realizada após isso uma regra de três simples para mensurar ganho ou perda na produtividade de cada um. 
Vale ressaltar que produção é a entrega de determinada atividade em um período de tempo, e produtividade é a redução desse período se comparado a meta estipulada. Para ilustramos, seguem na imagem abaixo os dados do colaborador 1.

\section{Produção:}

$$
\begin{array}{rrcc}
\text { Tempo Estimado --> } & 11: 30 & -- & 100 \\
\text { Tempo Execução --> } & 08: 00 & -- & x \\
11: 30 x & = & 800 \\
& x & = & 800,0 \\
\cline { 2 - 2 } & & \\
& x & =69,56 \%
\end{array}
$$

\section{Produtividade: $100-69,6=>30,4 \%$}

Figura 5: Regra de 3 para o cálculo do ganho de produtividade

Obtivemos no total, doze planilhas, duas referentes a cada um dos seis participantes do projeto piloto. Realizamos com cada uma das planilhas as etapas já informadas, e após isso, unimos em uma planilha todo o resultado obtido através das mesmas, para que a visualização do resultado fosse mais simples.

$\mathrm{Na}$ segunda etapa, tratamos os dados através da análise de conteúdo. Segundo Flick (2004), a análise de conteúdo é um dos métodos mais utilizados para o tratamento de dados textuais. Nessa etapa, realizamos a mesma forma de estruturação da anterior, sendo assim, realizamos primeiramente a organização do material, após isso a análise e exploração do conteúdo e por fim o tratamento e interpretação dos resultados. Apesar de realizarmos uma estruturação similar a etapa anterior, agora possuímos dados qualitativos, o que nos obrigou a ter uma postura diferente no tratamento dos mesmos.

Primeiramente, organizamos as respostas dos gestores de acordo com a ordem, ou seja, unindo todas as respostas aos questionamentos similares. Após isso, buscamos similaridades nas respostas que pudessem nos trazer um padrão, organizando-as de acordo com o mesmo. 
Ao analisar o conteúdo, utilizamos duas técnicas, a sumarização ou abreviação, reduzindo o material de forma a restar apenas o essencial, e a estruturação, que busca estabelecer estruturas formais no texto.

Por fim, chegamos aos resultados, que apesar de não possuírem métricas claras, nos foi de muita valia para o desenvolvimento e estruturação do estudo.

\subsection{Limitações do Estudo}

$\mathrm{Na}$ primeira etapa antevê-se que apesar de considerarmos o método escolhido como o mais adequado, tivemos algumas dificuldades para a coleta e tratamento dos dados. Em função dos funcionários serem de cargos diferentes e exercerem funções distintas, ao mensurarmos os critérios, avaliamos como base horas trabalhadas e não atividades propriamente ditas, o que pode nos levar uma conclusão tendenciosa, pois talvez a execução de uma determinada tarefa pode ser mais complexa que a outra, o que se olharmos apenas para horas trabalhadas, não enxergamos. Seria importante uma parametrização não só de horas trabalhadas, mas também de tarefas, para sabermos ao certo se a produtividade sofre melhora independente do cargo. Para tentar minimizar esse erro, buscamos uma verificação individual ao invés de grupal, para tentar identificar melhora em todos os funcionários estudados.

$\mathrm{Na}$ segunda etapa a dificuldade se faz mais clara ainda, tendo em vista que, no quesito absenteísmo não possuímos métricas estabelecidas e nem formas confiáveis de controle, o que dificulta nossa medição, sendo assim, ficamos restritos a percepções dos gestores, que apesar de sensatas e padronizadas, correm o risco de estarem enviesadas. Buscando minimizar esse erro, tentamos buscar equilíbrio e padrões nas respostas dos gestores, além de produzir questionamentos bastante diretos, evitando que o assunto se confunda com outros, buscando eliminar o viés. 


\section{Apresentação e análise dos resultados}

Este capítulo, organizado em quatro seções apresenta e discute os principais resultados alcançados, analisa e discute suas implicações e produz sugestões sobre o estudo previamente selecionado.

A primeira seção apresenta e descreve a Furnas Centrais Elétricas S.A., empresa escolhida para o estudo.

A seguir trata-se da descrição da amostra e definição do perfil dos entrevistados.

A terceira seção trás a descrição e análise da etapa quantitativa.

E por fim, a quarta e última seção trás a descrição e análise dos resultados da etapa qualitativa.

\subsection{A Empresa}

A empresa que foi objeto de estudo chama-se Furnas Centrais Elétricas S.A., mas também é conhecida como Eletrobrás Furnas e está sediada em Botafogo, na cidade do Rio de Janeiro. Atua no setor elétrico desde 1957, estando presente nas regiões Sudeste, Sul, Centro-Oeste e Norte do Brasil. Possuem doze usinas hidrelétricas, duas termoelétricas, 55 subestações e mais de $19000 \mathrm{~km}$ de linhas de transmissão, sendo responsável por suprir $51 \%$ das residências brasileiras. A empresa é de economia mista, subsidiária da Eletrobrás, e vinculada ao Ministério de Minas e Energia.

Possui atualmente cerca de 4500 colaboradores, que não estão habituados a realizar trabalho remoto. No entanto, as áreas competentes estão estudando a viabilidade de implementar esse modelo, tendo em vista a possibilidade aberta pela nova Lei Trabalhista.

Segundo comentários extraídos das entrevistas, a cultura da empresa é conservadora, e projetos dessa natureza são relevantes para mudar as práticas de trabalho e minimamente oferecer alternativas que visem o aumento de produtividade. 


\subsection{Descrição da amostra / do perfil dos entrevistados}

Na primeira etapa, o estudo foi de forma quantitativa, e selecionamos seis funcionários, que fizessem parte da área de Tecnologia da Informação, porém, com cargos variados. Os selecionados deveriam exercer funções/atividades que fossem possíveis mensurar tempo para execução, para que assim pudéssemos contabilizar aumento ou perda de produtividade.

$\mathrm{Na}$ segunda etapa, o estudo foi de forma qualitativa, sendo selecionados três gerentes da área de Tecnologia da Informação, para que pudéssemos inferir a partir de suas percepções aumento ou diminuição dos índices de absenteísmo após implementação do método de trabalho remoto.

\subsection{Descrição e análise dos resultados do método quantitativo}

Após o tratamento dos dados obtidos a partir das planilhas de controle de tarefas preenchidas e entregues ao fim do mês de testes pelos funcionários, foi possível a montagem de uma tabela mensurando os resultados apresentados.

Importante ressaltar que, apesar do proposto ter sido que cada participante realizasse quatro dias de trabalho remoto no mês, alguns não conseguiram trabalhar de forma remota os quatro dias propostos. O colaborador 3 conseguiu realizar suas atividades em três dias, reduzindo o prazo estimado. Já seu colega colaborador 4, devido à greve, que impossibilitou o funcionamento do sistema, não conseguiu trabalhar o último dia. Por fim, o colaborador 6 não tinha atividade que fosse possível estimar o tempo de execução.

Para apontarmos ganho ou perda de produtividade, levamos em conta dois aspectos que são horas estipuladas para a realização da atividade e horas utilizadas para a realização propriamente dita. Como dito anteriormente, cada colaborador teve metas estipuladas para cada um dos quatro dias baseadas em horas trabalhadas para podemos inferir a produtividade no período. Vamos utilizar como exemplo a coluna do quarto dia trabalhado pelo colaborador 2 .

O colaborador 2 tinha como meta a atividade "análise e planejamento da implantação do catálogo de serviços da Rede Operativa", estipulada em 8 horas 
para a sua realização. Apesar do período apontado, ao realizar a atividade de maneira remota, pode focar suas forças unicamente em tal tarefa, conseguindo realizá-la em apenas 6 horas. Aplicando uma regra de três simples onde 8 horas corresponde a $100 \%$ do período e 6 horas equivale a $x$, temos que $x$ é igual a $75 \%$. Portanto, precisou de apenas $75 \%$ do período para a realização da atividade. Levando em conta que mensuramos a produtividade a partir das horas trabalhadas, se diminuirmos o período trabalhado por ele de $100 \%$ que seria 0 período total de tempo disponível, notamos que o mesmo teve um ganho produtivo de $25 \%$ do período.

Realizando os mesmos cálculos para os demais colaboradores, chegamos à porcentagem de produção e porcentagem de ganho de produtividade de cada um deles. Somando a porcentagem trabalhada por cada um dos colaboradores nos quatro dias e dividindo pelo mesmo período, no caso quatro dias, chegamos à média de produção de cada um deles, e, somando o ganho de produtividade de cada um dos colaboradores e dividindo pelos quatro dias, obtivemos a média de ganho produtivo dos mesmos.

Por fim, somando a produtividade de todos os colaboradores, e dividindo por seis, que seria a quantidade de colaboradores, chegamos a média de ganho produtivo do projeto piloto. Com a mensuração dos dados chegamos a seguinte tabela:

\begin{tabular}{|c|c|c|c|c|c|c|c|c|}
\hline \multicolumn{9}{|c|}{ Média Estimada / Realizada } \\
\hline & & 1 & 2 & 3 & 4 & 5 & 6 & \multirow{17}{*}{$\begin{array}{l}\text { Média } \\
\text { Geral }\end{array}$} \\
\hline \multirow[t]{4}{*}{ 10 Dia } & Estimada & $11: 30$ & $22: 30$ & $07: 30$ & $09: 59$ & $07: 30$ & $07: 30$ & \\
\hline & Realizada & $08: 00$ & $07: 00$ & $08: 00$ & $05: 34$ & $06: 00$ & $04: 30$ & \\
\hline & Produção \% & 31,1 & 31,1 & 106,7 & 55,8 & 80,0 & 60,0 & \\
\hline & Produtividade $\%$ & 30,4 & 68,9 & & 44,2 & 20,0 & 40,0 & \\
\hline \multirow[t]{4}{*}{ 20 Dia } & Estimada & $19: 30$ & $36: 30$ & $15: 00$ & $10: 30$ & $07: 30$ & $15: 00$ & \\
\hline & Realizada & $09: 30$ & 09:00 & $07: 53$ & $06: 45$ & $07: 30$ & $07: 00$ & \\
\hline & Produção \% & 48,7 & 24,7 & 52,6 & 64,3 & 100,0 & 46,7 & \\
\hline & Produtividade $\%$ & 51,3 & 75,3 & 47,4 & 35,7 & 0,0 & 53,3 & \\
\hline \multirow[t]{4}{*}{ 3 Dia } & Estimada & $09: 30$ & $40: 00$ & $15: 00$ & $11: 05$ & $07: 30$ & & \\
\hline & Realizada & $06: 30$ & $8: 00$ & $10: 16$ & $08: 21$ & $08: 00$ & & \\
\hline & Produção \% & 68,4 & 20,0 & 68,4 & 75,3 & 106,7 & & \\
\hline & Produtividade $\%$ & 31,6 & 80,0 & 31,6 & 24,7 & & & \\
\hline \multirow[t]{4}{*}{40 Dia } & Estimada & $08: 30$ & $08: 00$ & & & $07: 30$ & & \\
\hline & Realizada & $06: 00$ & $06: 00$ & & & $07: 30$ & & \\
\hline & Produção \% & 70,6 & 75,0 & & & 100,0 & & \\
\hline & Produtividade $\%$ & 29,4 & 25,0 & & & 0,0 & & \\
\hline \multicolumn{2}{|c|}{ Média de Produção \% } & 64,3 & 37,7 & 113,8 & 65,1 & 96,6 & 53,3 & 87,9 \\
\hline \multicolumn{2}{|c|}{ Média Produtividade $\%$} & 35,7 & 62,3 & 39,5 & 34,9 & 3,4 & 46,7 & 39,8 \\
\hline
\end{tabular}

Figura 6: Tabela de Produtividade 
Os dados em vermelho apontam que os funcionários trabalharam além da meta prevista, logo, desconsideramos para o cálculo de produtividade.

Com base na tabela anterior e visando uma melhor visualização, elaboramos o seguinte gráfico de produtividade:

\section{Produtividade}

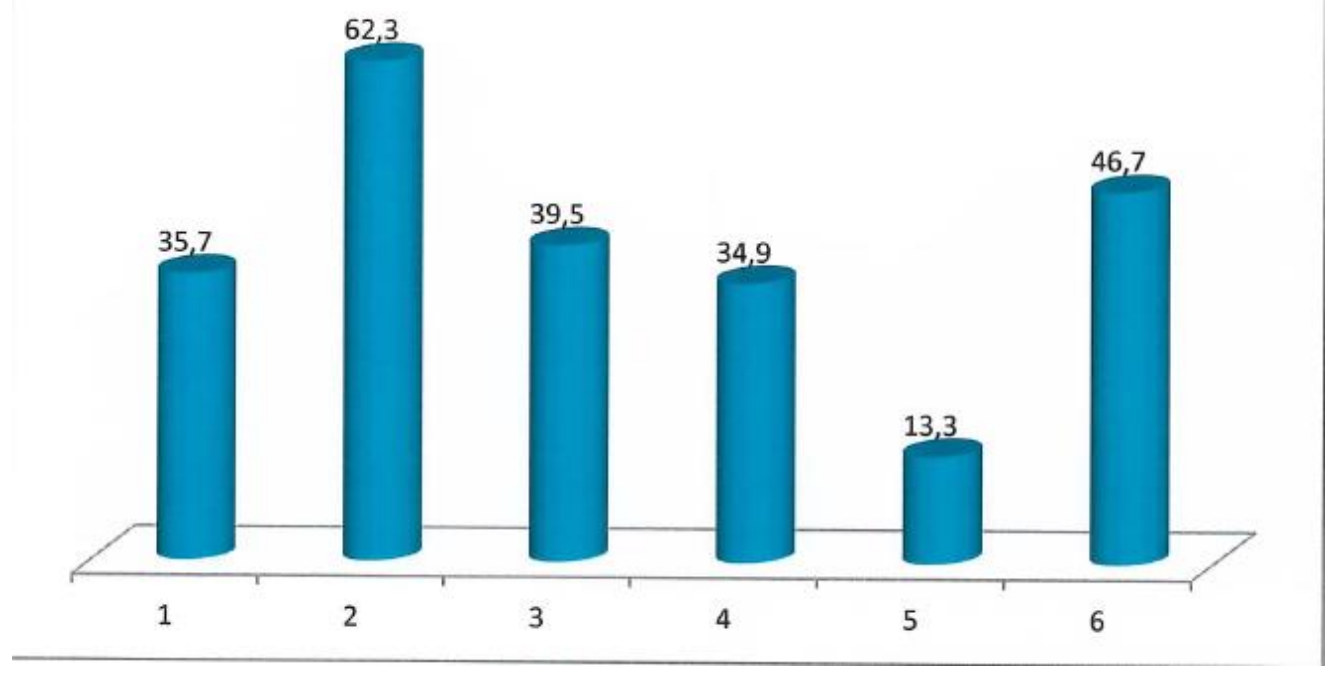

Figura 7: Gráfico de ganho produtivo dos participantes do projeto piloto

A média final de ganho de produtividade do projeto piloto, como podemos perceber na tabela anterior, foi de $39,8 \%$.

Após o fim dos testes, enviamos fichas para os participantes para que eles pudessem dar sua opinião quanto a execução e os resultados do estudo, e dentre os relatos obtidos, gostaríamos de salientar dois casos para comprovar que além do aumento da produtividade, há outros fatores importantes da implantação do método de trabalho remoto, como a redução dos custos.

O primeiro é o do Colaborador 2, que conseguiu executar uma tarefa, que havia sido estipulada por uma consultoria contratada por Furnas em 40 horas, no período de apenas 8 horas. Ao contratar uma consultoria, a hora custaria $R \$$ 137,00 , multiplicando pelo prazo de 40 horas, teríamos um custo total de $R \$$ 5480,00 . Com a redução de 32 horas para a execução da mesma, ele conseguiu uma economia de $\mathrm{R} \$ 5000,00$ para Furnas, conforme pode ser notado na ficha abaixo. 


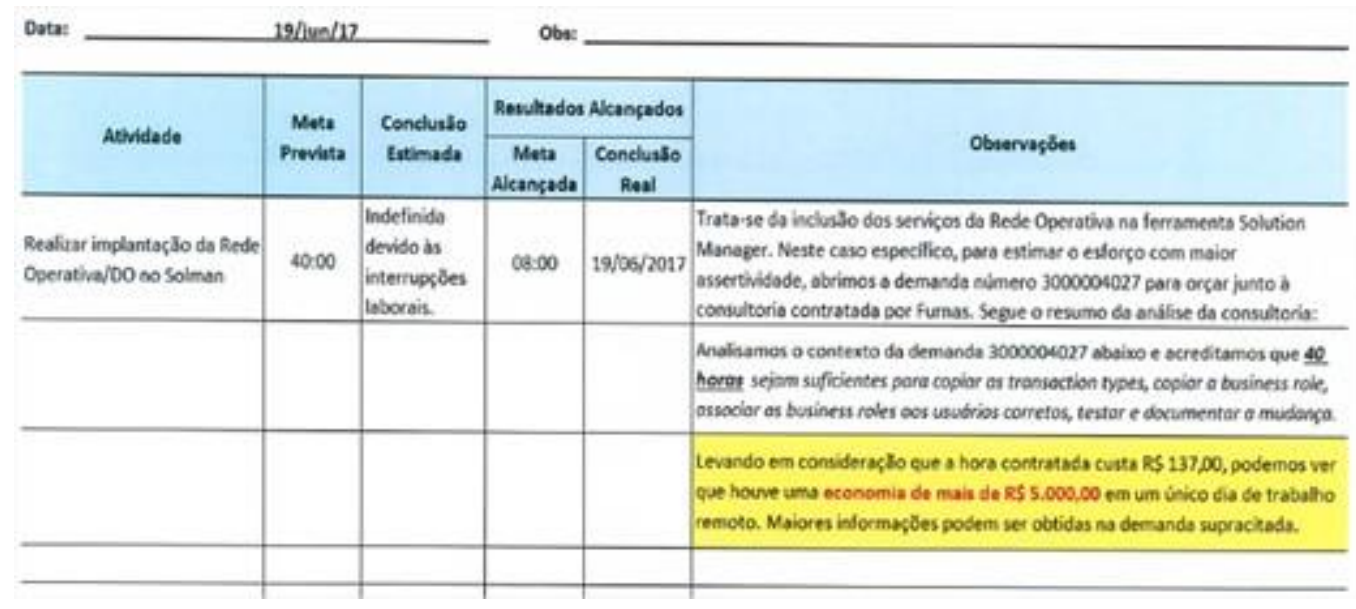

Figura 8: Ficha de controle de atividades

O segundo é do colaborador 5 , que reside em Teresópolis, o que gera um custo altíssimo para a empresa em transporte, e o fato dele trabalhar remotamente, sem precisar de deslocamento gerou em quatro dias, uma economia de aproximadamente $\mathrm{R} \$ 320,00$ para Furnas, conforme vemos abaixo.

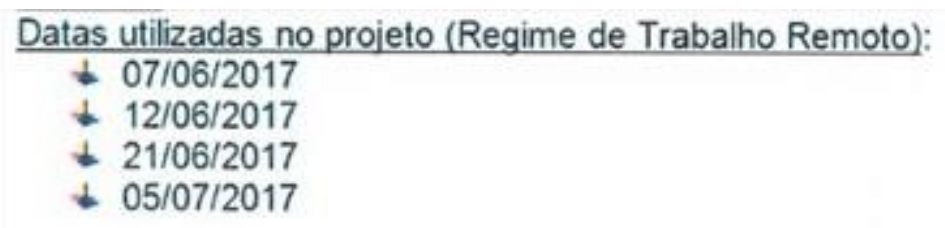

\section{Principais beneficios para a Empresa:}

$\checkmark$ Economia de aproximadamente R\$ 320.00 em vale-transporte por quatro dias;

$\checkmark$ Economia de R\$ 157,48 em auxilio alimentação por quatro dias;

$\checkmark$ Garantia do cumprimento de metas/atividades melhorando o controle da produtividade

Figura 9: Redução de custo propiciado pelo trabalho remoto

Com base nos relatos anteriores, podemos notar que, apesar do foco do projeto estar na produtividade, podemos perceber aspectos positivos diversos na sua implementação, o que corrobora com o nosso objetivo final. 


\subsection{Descrição e análise dos resultados do método qualitativo}

Após realizarmos a abreviação e a estruturação do material, chegamos a um padrão que engloba as respostas dos três gestores questionados.

Importante apontar que se trata de uma pesquisa de opinião, ou seja, buscamos a percepção dos gestores quanto ao absenteísmo apresentado no projeto piloto.

Quanto ao tema absenteísmo, os três acreditam que a implementação do modelo de trabalho remoto, pode sim causar uma diminuição em tais índices, pois, o mesmo tem como objetivo o foco na produção, e não no período trabalhado, portanto, possibilitando que o colaborador continue produzindo, independente da ida ou não ao trabalho. Como podemos notar na fala do gerente 3, Gerente Substituta:

Sinceramente acredito que o trabalho remoto vá diminuir a falta no trabalho. Mesmo porque o colaborador não ficará de folga em casa. Todo o processo de trabalho remoto esta baseado em metas e entregáveis. Obvio que a pessoa fica com mais liberdade de fazer outras coisas. O importante neste tipo de trabalho e cumprir as metas. O trabalho remoto está baseado em produtividade.

Outro ponto importante, apontado pelo gerente 1, é o fator motivação, auxiliando na melhor organização do tempo, como vemos no relato a seguir:

Como o colaborador consegue cumprir seu plano de trabalho para o dia remoto, ele se sente mais motivado e, muitas vezes, até consegue adiantar outras tarefas. Com isso, consegue tempo para se dedicar a tarefas mais "nobres" nos dias presenciais, o que faz com que sua motivação aumente ainda mais e, consequentemente, reduza suas ausências.

Corroborando com as respostas anteriores, o gerente 2, aponta que o ponto importante do trabalho remoto é a produtividade e não o período de trabalho, como podemos notar na passagem a seguir:

Considero que a produtividade é um indicador importante para a aferição do resultado do modelo, independente do tempo dedicado pelo profissional na execução das atividades remotas.

Portanto, nota-se claramente que na visão dos gestores diretamente ligados ao Furnas Remote, além do absenteísmo se tornar uma discussão ultrapassada quando o tema é trabalho remoto, certamente é um índice que 
tende a cair, uma vez que o funcionário se torna mais motivado, impedindo que problemas rotineiros que ocasionam a falta no trabalho, como estresse e dificuldade de locomoção afetem os mesmos.

No caso específico do Furnas Remote não foram determinados índices de absenteísmo para comparação com a situação anterior a implementação do método, pois o projeto focou-se na produtividade propriamente dita. 


\section{Conclusões e recomendações para novos estudos}

Este capítulo resume as principais contribuições produzidas ao tema em estudo.

O mercado mundial apresenta um perfil cada vez mais dinâmico e somados a globalização, torna-se complicado a adequação aos mesmos, o que passou a ser nos últimos anos, fator primordial de sucesso para as organizações. Atualmente, os colaboradores precisam estar sempre preparados para essas mudanças e possuir a capacidade de se adequar de maneira rápida, evitando a perda de produtividade acarretada por essas alterações, porém, os formatos atuais de trabalho, fazem com que seja um grande desafio obter funcionários com tais características. A partir daí as organizações vem buscando alternativas para os modelos atuais de trabalho, e é embasado nessa dificuldade que surge o nosso problema de pesquisa.

Trazemos como opção aos formatos atuais o Trabalho Remoto, e temos como objetivo maior desse trabalho de conclusão de curso, constatar que quando implantado tal modelo em uma grande organização, conseguimos um crescimento na produtividade da mesma.

Para embasarmos nosso estudo, buscamos entender alguns temas que consideramos pertinentes ao Trabalho Remoto. Primeiramente, apresentamos a ideia de Trabalho e Tecnologia na Contemporaneidade, baseados nas teorias de Bauman (1999; 2001), Sennett (2006) e Castells (1999). Seguindo por esse caminho, investigamos o tema Trabalho Remoto a fundo, investigando sua origem nos EUA, passando por estudiosos do tema como Jack Nilles (1997), Mello (1999) e Sobbratt, até chegarmos ao momento atual no Brasil, estando o tema já regulamentado pela Lei no 13.467 da CLT.

O trabalho remoto visa uma mudança total de paradigmas nas grandes organizações, tanto nas relações de trabalho quanto na cultura, e por essa razão, nos aprofundamos no tema Cultura Organizacional, utilizando como base dessa investigação a obra de Chiavenato, o grande pensador do tema. Após isso focamos no objetivo central do nosso estudo, a produtividade, fundamentados nos estudos de Neto (2009), Deming (1990), Tirone (1993) e 
Moller (2012). Por fim, tratamos do tema Absenteísmo, que apesar de não ser nosso foco principal e ser de difícil aferição, está diretamente relacionado tanto a cultura organizacional quanto ao trabalho remoto.

Para alcançarmos os objetivos determinados no estudo, optamos por um estudo parcialmente quantitativo e parcialmente qualitativo.

$\mathrm{Na}$ primeira etapa, realizamos um estudo quantitativo, que consistiu em uma pesquisa exploratória de campo, bibliográfica e documental. Foi implementado um projeto piloto que foi denominado Furnas Remote, visando a adoção por parte da área de Tecnologia da Informação da empresa Furnas. Nele foram selecionados seis funcionários que realizassem atividades que tivessem a possibilidade de definição de metas baseadas em horas trabalhadas, os mesmos receberam duas planilhas de controle de atividades cada, para preencherem de acordo com suas atividades nos quatro dias mensais de trabalho remoto que seriam realizados. Tratamos os dados obtidos de três maneiras, primeiro analisamos e exploramos o conteúdo, em segundo organizamos o material estudado e por fim interpretamos os resultados obtidos.

$\mathrm{Na}$ segunda etapa, realizamos um estudo qualitativo, que consistiu em uma pesquisa descritiva de campo, pois nos baseamos nas percepções dos gestores envolvidos no projeto, apresentadas em entrevistas realizadas com os mesmos. Após a realização das entrevistas, utilizamos duas técnicas, a sumarização, reduzindo o material e deixando apenas o que era realmente significativo ao estudo, e a estruturação, buscando estabelecer estruturas formais nas respostas. Por fim, organizamos um padrão de respostas e após esses pontos, chegamos aos resultados propriamente ditos.

Notamos que apesar de se tratar de uma forma menos padrão de trabalho, existe diversos ganhos tanto para a organização quanto para os funcionários.

Para a empresa, as vantagens são evidentes, tendo redução de $20 \%$ no transporte; 20\% em alimentação; redução de recursos destinados às instalações; economia com plano de saúde, se pensado em longo prazo; redução de desperdício de tempo; geração de motivação, pois se torna uma forma de reconhecimento do funcionário; aumento em mais de $30 \%$ da produtividade dos colaboradores.

Para os funcionários, as vantagens também são vastas, pois os mesmos passam a ter uma maior autonomia na administração do tempo trabalhado e do tempo remetido aos demais aspectos de sua vida; há redução no deslocamento diário, o que pode representar um ganho de 4 horas por dia; e com o equilíbrio 
entre vida pessoal e trabalho, além da redução do estresse, gera-se motivação o que aumenta o desempenho.

A consequência aos aspectos citados é o que buscamos constatar nesse estudo, a produtividade. Porém, vale ressaltar que para o alcance de tal ponto, o modelo requer do colaborador muita disciplina no gerenciamento do seu tempo.

Pesando os aspectos positivos e negativos, é necessário bom senso. Nesse estudo, obtivemos resultados satisfatórios que comprovam a eficácia do trabalho remoto, mas para isso, o Brasil precisa construir essa cultura inovadora.

A partir dos aspectos citados, chegamos a pergunta problema que nos propomos a responder nesse trabalho de conclusão de curso:

\section{A adoção do trabalho remoto pode aumentar a produtividade de uma organização?}

Embasado no projeto piloto realizado e nos resultados obtidos com o mesmo, fica evidente que a implementação do modelo de trabalho remoto em uma organização, gera um ganho produtivo tanto para os colaboradores como para a instituição como um todo. No caso específico em estudo, além do ganho individual de produtividade dos colaboradores, a organização Furnas teve um ganho de $39,8 \%$ de produtividade, e que caso o projeto seja implementado nas demais áreas da empresa, pode gerar um ganho imensurável para a mesma.

O trabalho remoto é uma realidade e certificadamente traz benefícios para o desenvolvimento econômico da organização e do país, contribuindo até mesmo para a preservação ambiental.

Por fim, fica a reflexão de que afinal, trabalho é algo a se realizar, não um local para aonde se vai.

\subsection{Sugestões e recomendações para novos estudos}

Como desdobramentos futuros, essa linha de estudo pode ser desenvolvida através de investigação sobre absenteísmo atrelado ao modelo. Como já explicado no estudo, apesar de trazermos conclusões sobre o tema, não focamos quantitativamente nele, apenas qualitativamente, o que pode nos enviesar na definição dos resultados. Portanto, um estudo quantitativo baseado em índices mais claros certamente é fundamental na discussão a respeito do assunto. 
Outra sugestão seria quanto à realização do estudo com uma amostra maior e mais homogênea, buscando uma melhor comparação quanto à produtividade, possibilitando assim a percepção de aspectos que não foram possíveis obtermos no estudo proposto.

Por fim, uma última sugestão seria a implantação do projeto piloto em outras áreas menos ligadas a tecnologia, buscando apontar se o trabalho remoto é específico para as áreas de Tecnologia da Informação ou pode ser utilizado por áreas menos específicas da organização. 


\section{Referências Bibliográficas}

BATISTA, M.B.B; ANTUNES, L.C.; IIZUKA, E.S.. Qualidade de Vida no Trabalho e a Produção Acadêmica: Visita aos Anais dos ENANPAD's de 2001 a 2011. In: EnANPAD, XXXVI, Rio de Janeiro. CD-ROM ANPAD. 2012.

BAUMAN, Z. O mal-estar da pós-modernidade. Rio de Janeiro: Zahar, 1998.

BAUMAN, Zygmunt. (1999). Globalização: As conseqüências humanas. Rio de Janeiro: Jorge Zahar.

BAUMAN, Zygmunt. (2001). Modernidade Líquida. Rio de Janeiro: Jorge Zahar.

BRASIL. Consolidação das Leis do Trabalho - Decreto-lei 5452/43 | Decreto-lei no 5.452, de $1^{\circ}$ de maio de 1943. Disponível em: https://presrepublica.jusbrasil.com.br/legislacao/111983249/consolidacao-dasleis-do-trabalho-decreto-lei-5452-43\#art-6. Acesso em 3 de maio de 2018.

BRASIL. Lei 12.551, 15 de dezembro de 2011. Altera o art. 6ㅇ da consolidação das Leis do Trabalho (CLT), aprovada pelo Decreto-Lei $n^{\circ} 5.452$, de 1ํㅡ de maio de 1943, para equiparar os efeitos jurídicos da subordinação exercida por meios elemáticos e informatizados à exervidad por meios pessoais e diretos. Disponível em http://www.planalto.gov.br/ccivil 03/ ato2011-2014/2011/lei/112551.htm Acesso 28 de maio de 2018.

BRASIL. Lei no 13.467, de 13 de julho de 2017. Disponível em: http://www.normaslegais.com.br/legislacao/Lei-13467-2017.htm. Acesso em 11 de abril de 2018.

CASTELLS, M. A sociedade em rede, a era da informação. 2. ed. São Paulo: Paz e Terra, 1999. (Economia, Sociedade e Cultura, v.1).

CHIAVENATO, Idalberto. Comportamento Organizacional: A dinâmica do sucesso das organizações. São Paulo: Manole, 2014.

CUCOLO, D. F.; PERROCA, M. G. Ausências na equipe de enfermagem em unidades de clínica médico-cirúrgica de um hospital filantrópico. Acta Paulista de Enfermagem, São Paulo, v. 21, n. 3, p. 454-459, 2008.

DE MELLO, Elizabeth Regina. Teletrabalho, Qualidade de Vida no Trabalho e Satisfação Profissional: Um estudo exploratório numa amostra de profissionais na área da Tecnologia da Informação. 2011. Tese (Mestrado Integrado em Psicologia) - Faculdade de Psicologia, Universidade de Lisboa, Portugal, 2011.

FERNANDES, R. L. et al. Absenteísmo em hospital filantrópico de médio porte. Semina: Ciências Biológicas e da Saúde, Londrina, v. 32, n. 1, p. 3-14, jan./jun. 2011. 
FERREIRA, C. R. et al. Abordagem multifatorial do absenteísmo por doença em trabalhadores de enfermagem. Revista de Saúde Pública, São Paulo, v. 46, n. 2, p. 259-268, abr. 2012.

Flick, U. (2004). Introducción a la investigación cualitativa. Madrid: Morata

Furnas, Quem somos. Disponível em:

http://www.furnas.com.br/frmEMQuemSomos.aspx. Acesso em 20 de maio de 2018.

Hom, Pesquisa da OIT mostra avanço do trabalho remoto no mundo. Disponível em: http://homeoffice.com.br/2017/02/24/pesquisa-da-oit-mostra-avanco-do-trabalhoremoto-no-mundo/. Acesso em 7 de abril de 2018.

MARTINATO, M. C. N. B. et al. Absenteísmo na enfermagem: uma revisão integrativa. Revista Gaúcha de Enfermagem, Porto Alegre, v. 31, n. 1, p. 160166, mar. 2010.

MELLO, A. Teletrabalho: o trabalho em qualquer lugar e a qualquer hora. Rio de Janeiro: Qualitymark, 1999.

MOLLER, Millene. Teletrabalho: Os efeitos das evoluções tecnológicas nas relações de trabalho. $60 \mathrm{f}$. Monografia (bacharelado) - Faculdade de Direito. UFRGS: Porto Alegre, 2012.

MURCHO, N. A. C.; JESUS, S. N.; PACHECO, J. E. P. Inventário de sintomas de mal-estar relacionados com o trabalho (ISMERT): um estudo prévio. Revista de investigação em Enfermagem, Coimbra, v. 17, p. 27-33, fev. 2008.

NILLES, Jack Mathias. Fazendo do teletabalho uma realidade: um guia para telegerentes e teletrabalhadores. Tradução Eduardo Pereira e Ferreira. São Paulo: Futura, 1997.

NILLES, Jack. Making Telecommuting Happen. USA: JALA International, Inc., 1994. PINEL, Maria de Fátima de Lima. Teletrabalho: o trabalho na era digital. Rio de Janeiro: Faculdade de Administração e Finanças, Universidade do Estado do Rio de Janeiro, 1998. (Dissertação de Mestrado em Ciências Contábeis).

PORTO, D. R.; PAULA, N. V. K. Estratégias de recursos humanos relacionados ao absenteísmo em profissionais de enfermagem. Revista Saúde e Pesquisa, Maringá, v. 3, n. 3, p. 365-370, set./dez. 2010.

REIS, Jair Teixeira. Subordinação jurídica e o trabalho à distância. São Paulo: LTr, 2007.

RIFKIN, Jeremy. O fim dos empregos: o declínio inevitável dos níveis dos empregos e a redução da força global de trabalho; trad. Ruth Gabriela Bahr. São Paulo: MAKRON Books do Brasil, 1996.

SATT, G.P.M; CRISTELLO, E.M. Motivação versus Produtividade: o impacto do fator motivação na produtividade das organizações. Anuário da Produção Científica dos Cursos de Pós-Graduação. v. IV, n. 4, 29-46, 2009. 
SCHIRIGATTI, Elisangela Lobo; KASPRZAK, Luis Fernando Fonseca. Home Office: Origem, Conceito e Interferências sobre o significado social do Novo Modelo de Trabalho Flexível. Revista Científica de Administração, v.8, n.8, jan./jun. 2007.

SENNETT, Richard. A cultura do novo capitalismo. Richard Sennett; tradução Clóvis Marques. - Rio de Janeiro: Record, 2006.

SOBRRAT, Home Office une qualidade de vida e produtividade. Disponível em:

http://www.sobratt.org.br/index.php/18032015-home-office-une-qualidade-devida-a-produtividade-2/. Acesso em 27 de abril de 2018.

SOBRATT, História. Disponível em:

http://www.sobratt.org.br/index.php/quem-somos/historia/. Acesso em 14 de abril de 2018.

TIRONI, L. F. Indicadores da Qualidade e Produtividade: Conceitos e Usos. Revista Indicadores da Qualidade e Produtividade. Brasília, DF: Instituto de Pesquisa Econômica Aplicada, v.1, n.2, set. 1993. Semestral.

UMANN, J. et al. Absenteísmo na equipe de enfermagem no contexto hospitalar. Ciência, Cuidado e Saúde, Maringá, v. 10, n. 1, p. 184-190, jan./mar. 2011.

University of Florida, TELECOMMUTING GUIDE, 17p. Disponível em http://fcn.state.fl.us/dins/pins/telegde.htm. Acesso em 11 de abril de 2018.

YAMAMOTO, Lays Yuri. Teletrabalho no segmento de tecnologia da informação: estrutura e proteção jurídica no ordenamento brasileiro. 2016. Tese de Láurea (Bacharel em Direito) - Faculdade de Direito, Universidade de São Paulo, São Paulo, 2016. 


\section{Anexo 1 - Exemplo de Ficha de Controle de Atividades}

Ficha de controle de atividade do participante Fabio.

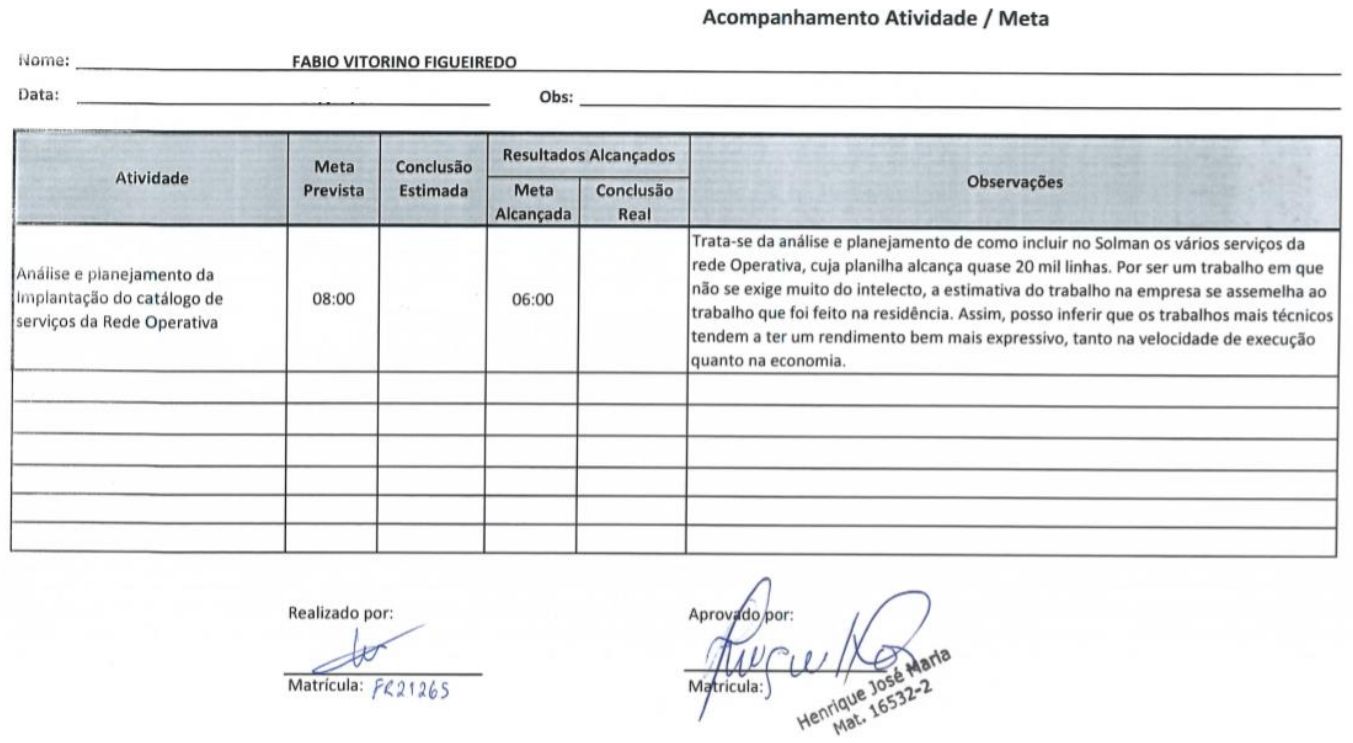




\section{Anexo 2 - Perguntas e respostas dos gerentes}

Perguntas e respostas dos gerentes que participaram do projeto piloto.

\section{Gerente 1}

Gerente Substituta

1- Em relação ao tema absenteísmo, na visão dos senhores, após a aplicação do método de trabalho remoto ocorre a diminuição de tais índices? Justifique.

R: Sim. Como o colaborador consegue cumprir seu plano de trabalho para o dia remoto, ele se sente mais motivado e, muitas vezes, até consegue adiantar outras tarefas. Com isso, consegue tempo para se dedicar a tarefas mais "nobres" nos dias presenciais, o que faz com que sua motivação aumente ainda mais e, consequentemente, reduza suas ausências.

2- Ainda sobre o tema, a ideia de trabalho remoto está diretamente ligada a produtividade e não tanto a periodicidade, o que pensam sobre isso?

R: Concordo. O que importa é o quanto será realizado e não a periodicidade. Entendo que trabalho é o que deve ser realizado e não o local onde as tarefas são realizadas.

Gerente 3

Gerente Substituta

1- Em relação ao tema absenteísmo, na visão dos senhores, após a aplicação do método de trabalho remoto ocorre a diminuição de tais índices? Justifique.

Sinceramente não acredito que o trabalho remoto vá diminuir a falta no trabalho. Mesmo porque o colaborador não ficará de folga em casa. Todo o processo de trabalho remoto esta baseado em metas e entregáveis. Obvio que a pessoa fica com mais liberdade de fazer outras coisas. O importante neste tipo de trabalho e cumprir as metas. $O$ trabalho remoto esta baseado em produtividade. 
2- Ainda sobre o tema, a ideia de trabalho remoto está diretamente ligada a produtividade e não tanto a periodicidade, o que pensam sobre isso?

Concordo plenamente, esta diretamente ligado a produtividade. Para o sucesso do trabalho remoto, devem ser definidas metas e entregáveis. O tempo não é importante. $\mathrm{O}$ importante é atingir as metas e até supera-las.

\section{Gerente 2}

Gerente de TI

1- Em relação ao tema absenteísmo, na visão dos senhores, após a aplicação do método de trabalho remoto ocorre a diminuição de tais índices? Justifique.

No período de aplicação do modelo em Furnas não houve variação no índice de absenteísmo.

2- Ainda sobre o tema, a ideia de trabalho remoto está diretamente ligada a produtividade e não tanto a periodicidade, o que pensam sobre isso?

Considero que a produtividade é um indicador importante para a aferição do resultado do modelo, independente do tempo dedicado pelo profissional na execução das atividades remotas. 